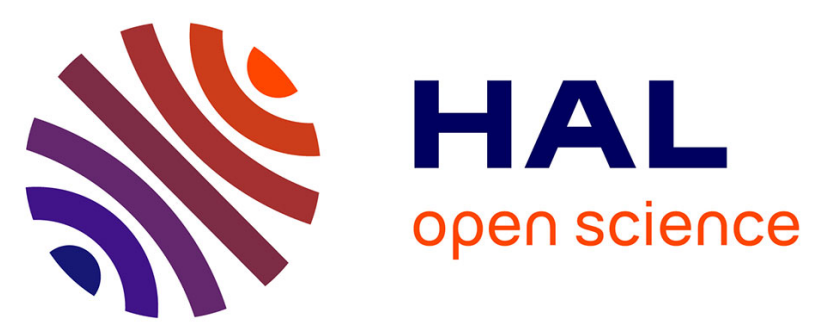

\title{
A surrogate model based on feature selection techniques and regression learners to improve soybean yield prediction in southern France
}

David Camilo Corrales, Céline Schoving, Hélène Raynal, P Debaeke, Etienne-Pascal Journet, Julie Constantin

\section{To cite this version:}

David Camilo Corrales, Céline Schoving, Hélène Raynal, P Debaeke, Etienne-Pascal Journet, et al.. A surrogate model based on feature selection techniques and regression learners to improve soybean yield prediction in southern France. Computers and Electronics in Agriculture, 2022, 192, pp.106578. 10.1016/j.compag.2021.106578 . hal-03454504

\author{
HAL Id: hal-03454504 \\ https://hal.science/hal-03454504
}

Submitted on 29 Nov 2021

HAL is a multi-disciplinary open access archive for the deposit and dissemination of scientific research documents, whether they are published or not. The documents may come from teaching and research institutions in France or abroad, or from public or private research centers.
L'archive ouverte pluridisciplinaire HAL, est destinée au dépôt et à la diffusion de documents scientifiques de niveau recherche, publiés ou non, émanant des établissements d'enseignement et de recherche français ou étrangers, des laboratoires publics ou privés. 


\title{
A surrogate model based on feature selection techniques and regression learners to improve soybean yield prediction in southern France
}

\author{
David Camilo Corrales ${ }^{\text {a, b * }}$, Céline Schoving ${ }^{\text {c }}$, Hélène Raynal ${ }^{\text {a }}$, Philippe Debaeke ${ }^{\text {a }}$, Etienne- \\ Pascal Journet ${ }^{\text {a, }}{ }^{\text {and Julie Constantin }}{ }^{\mathrm{a}}$ \\ ${ }^{a}$ Université de Toulouse, INRAE, UMR AGIR, F-31326, Castanet-Tolosan, France \\ ${ }^{b}$ Grupo de Ingeniería Telemática, Universidad del Cauca, Sector Tulcán, Popayán, Colombia \\ ${ }^{c}$ Terres Inovia, Baziège, France \\ ${ }^{d}$ Université de Toulouse, INRAE, CNRS, LIPME, F-31326, Castanet-Tolosan, France \\ *Corresponding author.E-mail address: davidcamilo.corralesmunoz@inrae.fr,dcorrales@unicauca.edu.co
}

\begin{abstract}
Empirical and process-based models are currently used to predict crop yield at field and regional levels. A mechanistic model named STICS (Multidisciplinary Simulator for Standard Crops) has been used to simulate soybean grain yield in several environments, including southern France. STICS simulates at a daily step the effects of climate, soil and management practices on plant growth, development and production. In spite of good performances to predict total aboveground biomass, poor results were obtained for final grain yield. In order to improve yield prediction, a surrogate model was developed from STICS dynamic simulations, feature selection techniques and regression learners. STICS was used to simulate functional variables at given growth stages and over selected phenological phases. The most representative variables were selected through feature selection techniques (filter, wrapper and embedded), and a subset of variables were used to train the regression learners Linear regression (LR), Support vector regression (SVR), Back propagation neural network (BPNN), Random forest (RF), Least Absolute Shrinkage and Selection Operator (LASSO) and M5 decision tree. The subset of variables selected by wrapper method combined with regression models $S V R\left(R^{2}=0.7102\right.$; subset of variables $=6)$ and $L R\left(R^{2}=0.6912\right.$; subset of variables $\left.=14\right)$ provided the best results. SVR and LR models improved significantly the soybean yield predictions in southern France in comparison to STICS simulations $\left(\mathrm{R}^{2}=0.040\right)$.
\end{abstract}

Keywords: STICS; regression learners; filter; wrapper; embedded

\section{1- Introduction}

Soybean (Glycine $\max$ L.) is grown on 125 million ha worldwide, with a total average production of 340 million tons on the 2016-2020 period (Oil Word, 2020). On an absolute basis, soybean is the fourth most important grain crop after wheat, maize and rice. USA, Brazil, and Argentina are the three most producing countries, accounting collectively for $81 \%$ of the global production (Grassini et al., 2021). EU-27 is a marginal producer (2.6 million tons, $<0.8 \%$ of world production), importing $c a .95 \%$ of its soybean domestic needs as rich-protein GMO (Genetically Modified Organisms) and non-GMO meals for animal feed. In Europe, France is the second most important producer after Italy (186 500 ha in 2020), the two main producing 
regions being South-West and Center-East parts with an increasing contribution of organicallygrown production. One main objective in France is to achieve self-sufficiency at least in nonGMO soybean meals at 2025 horizon. Therefore, EU-27 members share a common objective: "reducing markedly the dependency upon soybean imports by developing European production". Soybean crop requires few pesticides, no N-fertilizer and less irrigation than maize, results in low emissions of greenhouse gases, hence bringing environmental benefits. In addition, it could contribute as a summer crop to the diversification of winter cereal-based systems.

Grain yield in France slightly increased since the 80s (Terres Univia, 2021). In 2019, yields

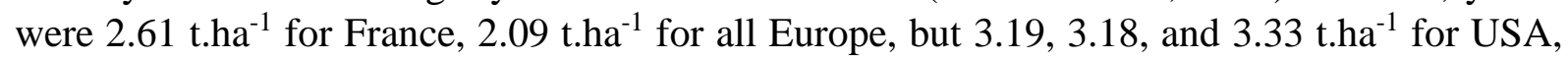
Brazil and Argentina respectively (FAOSTAT, 2021). Climate change and its impacts on temperature, precipitation, and $\mathrm{CO}_{2}$ concentration, but also on water resources available for irrigation, will certainly impact the future production (Porter et al., 2014; Guilpart et al., 2020; Kothari et al., 2020). In addition, expanding soybean growing areas northward and introducing new cropping systems (e.g. double cropping with cereals, rainfed or irrigated soybean, etc.) will change the potential and attainable grain yields.

Therefore predicting soybean yield in various environments and a range of cropping systems will be necessary to evaluate the ability of France and European countries to achieve their objectives in terms of protein self-sufficiency by growing more soybean in cropland. Modeling can be efficient in yield analysis and investigation of the limiting factors due to easy manufacturing, testing, applying, understanding and interpretation of results (Nehbandani et al., 2020).

Yield prediction models are based on historical or future climate data for evaluating production potentials; also, yield prediction models assimilate remote sensing information when applied to in-season prediction. Nowadays, both statistical and mechanistic approaches are used in agricultural modelling, especially for yield prediction. Statistical approaches search and explore the relations between data to explain the variables of interest whereas mechanistic models are based on the description of biophysical processes. Dynamic crop models simulate daily growth and development in relation with environmental resources and agricultural inputs; they allow the testing of functional hypotheses and the identification of potential constraints to crop growth and yield (Purcell \& Roekel, 2019). However, mechanistic and statistical approaches can be combined in order to improve the crop modeling predictions (Casadebaig et al., 2011, 2020).

Statistical models from traditional Artificial Neural Networks (ANN) and Deep Learning (DL) have been used for soybean yield prediction. ANN models were proposed by (Kaul et al., 2005) in order to predict Maryland soybean yield at state, regional, and local levels. ANN were developed using historical yield data (1978-1998). Field-specific rainfall data and Soil Rating for Plant Growth (SRPG) values were used for each location. The work developed in (Maimaitijiang et al., 2020) estimated the soybean grain yield through multispectral images (information type: canopy spectral, structure, thermal and texture features) and DLN in Columbia, Missouri. A Convolutional Neural Network (CNN) for soybean yield prediction in 15 states of CONUS (United States) is proposed in (Sun et al., 2019). The model was trained by crop growth and environment variables, which include weather data, MODIS Land Surface Temperature data, and MODIS Surface Reflectance data. In Cachoeira do Sul, Brazil, a MultiLayer Perceptron (MLP) was used to adjust a predictive model for estimating the yield of 
soybean crop based on 9 vegetation indices (Eugenio et al., 2020). A soybean yield model was created by deep learning framework using $\mathrm{CNN}$ and recurrent neural networks (Khaki et al., 2020). Model was built based on environmental data and management practices from Corn Belt (including 13 states) in the United States. In southern Brazil different type of indices as Normalized Difference Vegetation Index (NVDI), Enhanced vegetation index (EVI), land surface temperature (LST) and precipitation were used to build a model using Long-Short Term Memory (LSTM), Neural Networks (Schwalbert et al., 2020). ANN was developed to evaluate the relative importance of predictor variables as vegetation indices (NDVI, red edge NDVI and simple ratio-SR) and elevation derived variables (slope, flow accumulation, aspect) for the prediction of soybean in Ontario, Canada (Kross et al., 2020).

Traditional regression models/analysis were used with the same purpose. Authors in (Stepanov et al., 2020) used backward stepwise in order to build a regression model in Khabarovsk, Russia. Several data sources were used as Moderate Resolution Imaging Spectroradiometer (MODIS), arable land mask and meteorological stations. The NDVI was used to improve soybean yield predictions using the flexible Fourier transform model in United States (Xu \& Katchova, 2019). The objective was to explore the relationships between soybean yield and number of grains (NG) and thousand grains weight (TGW), generate equations to estimate yield in several countries in the years 2010 and 2019 (Wei \& Molin, 2020). A regression analysis was developed by (Ma et al., 2001) in order to study the correlations between plant canopy reflectance and aboveground biomass for early prediction of soybean yield in Canada.

In addition, mechanistic models were calibrated in order to predict soybean yield. Authors in (Robertson \& Carberry, 1998) used Agricultural Production Systems Simulator (APSIM) with aim to simulate the soybean yield. The model was tested on an independent set of experiments, from northern Australia, with factors such as cultivars, sowing date, irrigation, soil type, plant population density row spacing varying. The research proposed by (Jagtap \& Jones, 2002) developed a procedure to simulate soybean yield and production by linking the CROPGROsoybean model with a regional resolution (about a $50 \mathrm{~km}$ grid cell) database of weather, soils, management, and varieties in the state of Georgia over the 1974-1995 time period. The CROPGRO-Soybean model was calibrated to estimate potential yields and yield gaps of soybean for 21 locations regions in India (Bhatia et al., 2008). Authors in (Ovando et al., 2018) simulated soybean yield using a DSSAT model through weather data from Clouds and Earth's Radiant Energy System (CERES) and Tropic Rainfall Measurement Mission (TRMM) for 2006 - 2016 in Oliveros, Argentina. In (Battisti et al., 2017), the model for Nitrogen and Carbon in Agroecosystems (MONICA) was used to simulate soybean grain yield for 14 sites in Southern Brazil. The models CSM-CROPGRO-Soybean and STICS (Multidisciplinary Simulator for Standard Crops) were used to simulate soybean yield responses under near (20412070) and distant (2071-2100) future climate scenarios in eastern Canada (Jing et al., 2017).

The AgMip initiative started an inter-comparison of 10 soybean crop models at 5 locations in major global production areas with high quality observed data for calibration (Kothari et al., 2020). Among the tested models, STICS (Brisson et al., 2009), a widely used soil-plant crop model applied on a wide range of crops (305 papers in Web of Science), appeared as moderately performing with a prediction gap. Previous attempts to validate STICS on soybean concluded to good performance in aboveground biomass prediction but poor results on grain yield and protein concentration (Schoving, 2020). In eastern Canada, (Jégo et al., 2010) obtained scattered results for biomass, LAI and yield, with Root Mean Square Error (RMSE) from 23 to 
$38 \%$. Heretofore, this model has been used less in soybean crops, but encouraging results were recently obtained through proper calibration on pea and faba bean, two other grain legumes (Falconnier et al., 2019, 2020). In addition, STICS describes with a good accuracy the dynamics of water and nitrogen in soils and a module was introduced for considering explicitly $\mathrm{N}_{2-}$ fixation in legumes.

Improving the STICS prediction for soybean could imply a thorough calibration of the model and/or a deep re-examination of the underlying biophysical processes. The experimental data required for such an improvement could be insufficient. The data-driven modeling approach has emerged as an alternative to model the biophysical system purely from the data available. A data-driven model, also known as a meta-model or surrogate model, is a "model of the model" (Cui et al., 2016). A surrogate model is a statistical model trained from simulations/variables difficult to measure in field (e.g. leaf area index, aboveground crop biomass, $\mathrm{N}$ crop uptake, crop transpiration, etc.). The surrogate model can be deployed to replace or support the original biophysical simulation module to accurately approximate the simulation output. Figure 1 explains the interactions between surrogate and STICS model.

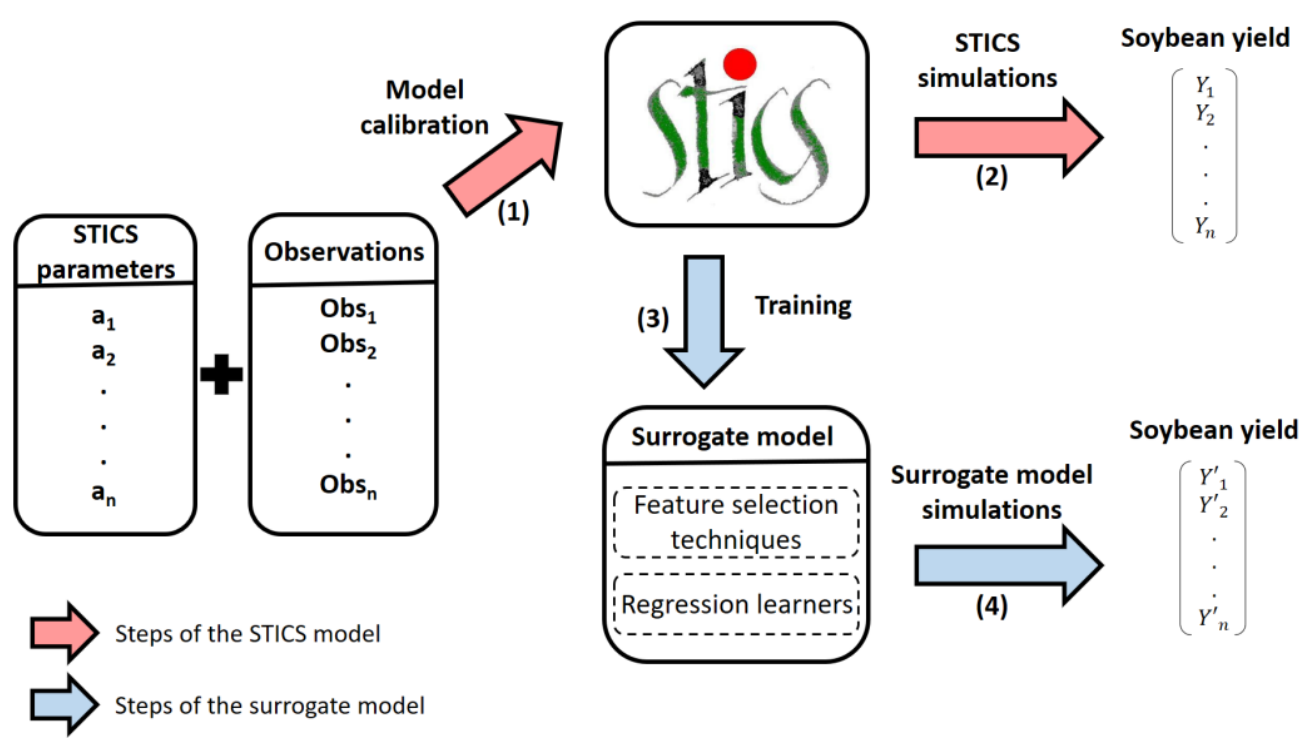

Figure 1. Steps of STICS and surrogate model to predict the soybean yield. The red arrows show the process of soybean yield simulations generated by STICS. (1) Parameters are calibrated and field observations are used to run STICS. (2) Soybean yield simulations $Y_{1}, Y_{2} \ldots, Y_{n}$ generated by STICS. The blue arrows depict the steps to create the surrogate model. (3) The STICS simulations are used to select the relevant variables and train the surrogate model. (4) Soybean yield simulations $Y^{\prime}{ }_{1}, Y^{\prime}{ }_{2} \ldots, Y^{\prime}{ }_{n}$ generated by the surrogate model.

In this sense, we proposed a surrogate model based on feature selection techniques and regression learners to predict soybean yield in southern France. The surrogate model is trained from the data produced by STICS simulations generated by (Schoving, 2020) (effects of climate, soil and management practices on dynamic variables of soybean crop functioning) to improve the prediction of final grain yield. This study progressed through three steps:

a) Calculate crop variables at different phenological stages with STICS as evaluated by (Schoving, 2020) in southern France.

b) Find the representative variables of soybean yield based on feature selection techniques.

c) Build a regression model to predict soybean yield based on representative variables found by feature selection techniques. 


\section{2- Materials and methods}

\section{Multidisciplinary Simulator for Standard Crops (STICS)}

The STICS model simulates at a daily step the effects of climate, soil and management practices on plant growth, development and production (quantity and quality) and environmental impacts. The combination of these input variables is termed a USM (Unit of SiMulation). Each USM corresponds to one execution of the STICS model (Brisson et al., 1998). STICS can be tuned to a single crop, two intercropped or several successive crop cycles. STICS has been evaluated over a large data set for 15 different crops and different conditions of soil and climate in France (Coucheney et al., 2015).

In order to calibrate STICS, the crop files contain species parameters, ecophysiological options (e.g. effect of photoperiod and/or cold requirements on crop phenology, potential radiation use efficiency) and cultivar specific parameters (e.g. flowering precocity, maximum number of grains per $\mathrm{m}^{2}$ ). Crop temperature (calculated from weather variables) and photoperiod drive crop phenology. The model dynamically simulates (i) the development of the root system that takes up $\mathrm{N}$ and water according to root density over the whole soil profile and (ii) the establishment of the canopy that transpires water and intercepts light to produce the crop biomass (Brisson et al., 2009).

\section{Study area and datasets}

The data used in this work were collected by (Schoving, 2020). Seventeen experimental sites were conducted during 2010-2018 from six regions in the south of France: Mauguio (2010), Béziers (2010 - 2012), Mondonville (2010 - 2014), Rivières (2010 - 2014), En Crambade (2013 - 2014) and Auzeville (2017 - 2018) as shown in Figure 2.

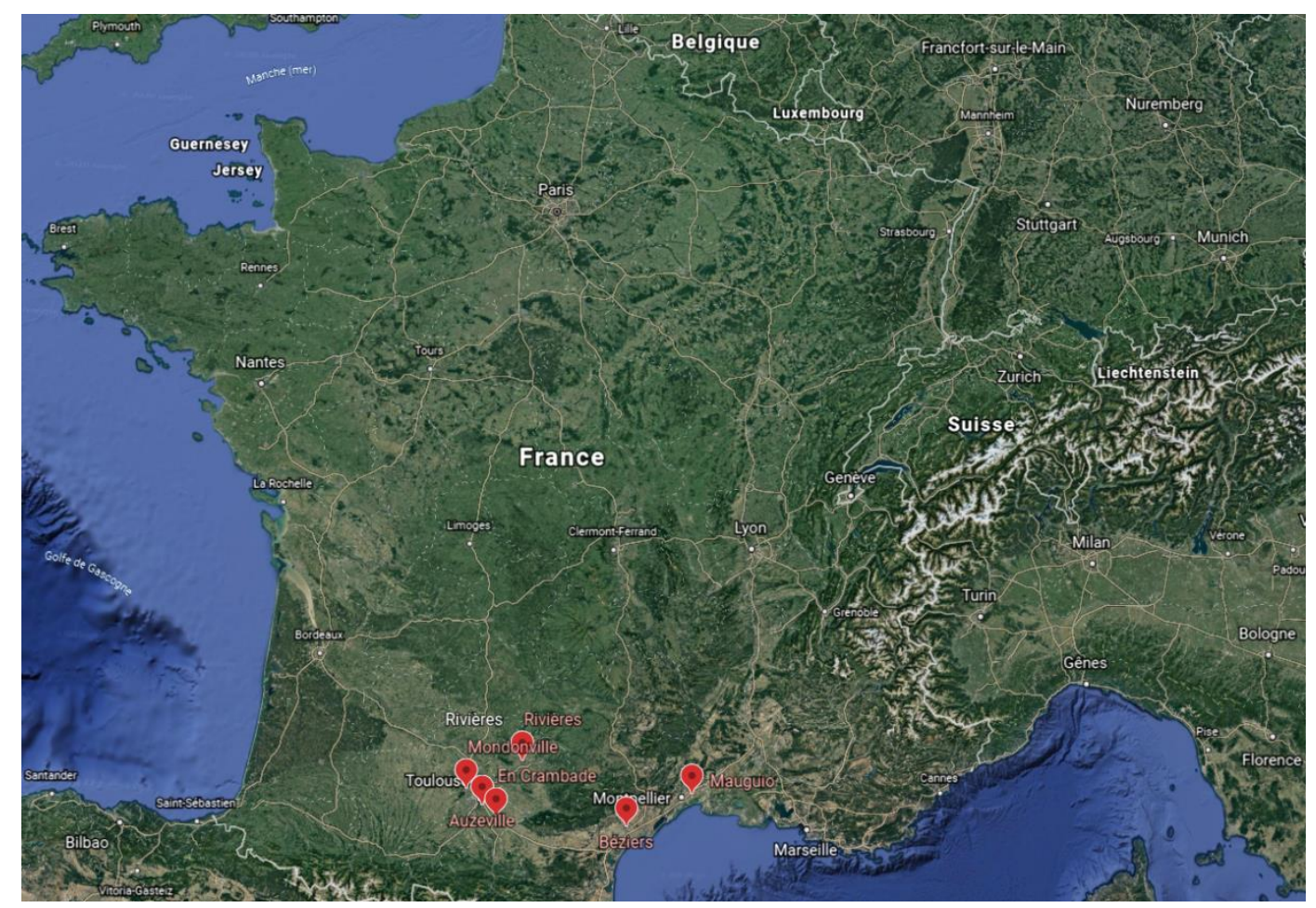

Figure 2. Locations in Southern France where experimental sites were conducted. Locations are depicted by red markers (Mauguio, Béziers, Mondonville, Rivières, En Crambade and Auzeville). This figure was created by Google Earth. 
The eleven tested soybean varieties belonged to four maturity groups corresponding to different crop durations and potential yields: 000 (very early-maturing), 0, I and II (late-maturing). Three late-maturing varieties were tested in all experiments since 2010 (Ecudor, Santana, Isidor and Sarema). Detailed information on varieties and maturity groups are presented in Table A1 (Appendix A). Weather data were collected near to the experimental sites. Soil samples contain texture and physico-chemical analyzes. These data are essential to correctly initialize STICS with realistic values of soil moisture and mineral nitrogen (nitrate, ammonium). The water pressure of the soils was monitored in a micro-plot of Santana variety, at 30, 60 and $90 \mathrm{~cm}$ depth.

The dataset contains 227 simulation units (USM) created from combination of experimental sites, years and cropping practices (cultivar, water management and sowing date); We used the same training (105 USMs) and test (122 USMs) datasets as defined by (Schoving, 2020). The train-test split was defined based on the number of variables measured in field by experimental sites (variables such as phenology, biomass, leaf area index, grain yield and seed protein content). Most complete observations measured in field were selected to train the surrogate model while data with less observations were retained for the test set. We preprocessed 87 variables based on agronomist knowledge from a selection of 19 STICS state variables calculated daily by the model during its simulation (Table 1). The preprocessed variables concern either state variables at different crop phenology stages (Ilev: emergence, Idrp: grain filling onset, Iflo: flowering, Imat: physiological maturity), descriptive values (Cum: cumulative, Max: maximum, Avg: average) and thresholds set for variables as MinTemp (days MinTemp $<18^{\circ} \mathrm{C}$ ), MaxTemp (days MaxTemp $>28^{\circ} \mathrm{C}$ ), Swfac (days Swfac < 0.6) and Inn (days Inn <0.6). The soybean grain yield is represented by variable Mafruit (Table 1; dependent variable).

\begin{tabular}{|c|c|c|}
\hline STICS variables & Units & Description \\
\hline Nbgrmax & $\mathrm{m}^{-2}$ & Maximal grain number \\
\hline Stlevdrp & ${ }^{\circ} \mathrm{C}$.days & Heat sum from emergence to grain filling onset \\
\hline Stflodrp & ${ }^{\circ}$ C.days & Heat sum from flowering to grain filling onset \\
\hline Stdrpmat & ${ }^{\circ}$ C.days & $\begin{array}{l}\text { Heat sum from grain filling onset to physiological } \\
\text { maturity }\end{array}$ \\
\hline $\operatorname{Masec}(\mathrm{n})$ & t.ha $a^{-1}$ & Aboveground crop biomass \\
\hline Lai(n) & $\mathrm{m}^{2} \cdot \mathrm{m}^{-2}$ & Leaf area index \\
\hline Qnplante & kg.hat ${ }^{-1}$ & Cumulative amount of $\mathrm{N}$ taken up by the crop \\
\hline Qfix & kg.ha ${ }^{-1}$ & Cumulative amount of $\mathrm{N}$ fixed by the crop \\
\hline Zrac & $\mathrm{m}$ & Water excess stress index on roots \\
\hline Jul & Julian day & Julian day \\
\hline Raint & MJ.m ${ }^{-2}$ & $\begin{array}{l}\text { Photosynthetic active radiation intercepted by the } \\
\text { canopy }\end{array}$ \\
\hline $\operatorname{Etpp}(n)$ & $\mathrm{mm} \cdot \mathrm{d}^{-1}$ & Daily potential evapotranspiration \\
\hline Precip & $\mathrm{mm} \cdot \mathrm{d}^{-1}$ & Precipitation \\
\hline Ep & $\mathrm{mm} \cdot \mathrm{d}^{-1}$ & Daily actual transpiration \\
\hline AvgTemp & ${ }^{\circ} \mathrm{C}$ & Average air temperature \\
\hline MinTemp & ${ }^{\circ} \mathrm{C}$ & Minimum air temperature \\
\hline MaxTemp & ${ }^{\circ} \mathrm{C}$ & Maximum air temperature \\
\hline Swfac & $0-1$ & Stomatal water stress index \\
\hline Inn & $0-2$ & Nitrogen nutrition index \\
\hline Mafruit & t.ha- ${ }^{-1}$ & Biomass of harvested organs (grain yield) \\
\hline
\end{tabular}


For instance, preprocessed variables computed by phenology stages as Lai(n)_Iflo variable indicates the leaf area index $\operatorname{Lai}(n)$ at flowering (Iflo). Other variables are expressed over phenophases, for example Precip_cum_Iflo-Imat represents the cumulative precipitation (Precip) between two phenological stages: flowering (Iflo) and physiological maturity (Imat). In addition, we define variables by phenophases and thresholds as Days_MinTemp_18_IlevImat variable which indicates the number of days when minimum temperature was less than $18^{\circ} \mathrm{C}$ between emergence and physiological maturity stages. Table 2 presents a summary of preprocessed variables from STICS by stages or phases, descriptive values and thresholds.

221 Table A2 (Appendix A) lists all of the preprocessed variables.

\begin{tabular}{|c|c|c|c|c|}
\hline $\begin{array}{c}\text { STICS } \\
\text { variables }\end{array}$ & Stages or phases & $\begin{array}{l}\text { Descriptive } \\
\text { value }\end{array}$ & Threshold & $\begin{array}{c}\text { Number } \\
\text { of } \\
\text { variables }\end{array}$ \\
\hline Nbgrmax & - & - & - & 1 \\
\hline Stlevdrp & - & - & - & 1 \\
\hline Stflodrp & - & - & - & 1 \\
\hline Stdrpmat & - & - & - & 1 \\
\hline $\operatorname{Masec}(n)$ & Iflo, Idrp, Imat & - & - & 3 \\
\hline Lai(n) & Iflo, Idrp, Imat & - & - & 3 \\
\hline Qnplante & Iflo, Idrp, Imat & - & - & 3 \\
\hline Qfix & Iflo, Idrp, Imat & - & - & 3 \\
\hline Zrac & Iflo, Idrp, Imat & - & - & 3 \\
\hline Jul & Ilev-Imat, Iflo-Imat, Idrp-Imat, Iflo-Idrp & Cum & - & 4 \\
\hline Raint & Ilev-Imat, Iflo-Imat, Idrp-Imat, Iflo-Idrp & Cum & - & 4 \\
\hline $\operatorname{Etpp}(n)$ & Ilev-Imat, Iflo-Imat, Idrp-Imat, Iflo-Idrp & Cum & - & 4 \\
\hline Precip & Ilev-Imat, Iflo-Imat, Idrp-Imat, Iflo-Idrp & Cum & - & 4 \\
\hline Ep & Ilev-Imat, Iflo-Imat, Idrp-Imat, Iflo-Idrp & Cum & - & 4 \\
\hline AvgTemp & Ilev-Imat, Iflo-Imat, Idrp-Imat, Iflo-Idrp & Avg & - & 4 \\
\hline MinTemp & Ilev-Imat, Iflo-Imat, Idrp-Imat, Iflo-Idrp & Avg & \# days MinTemp $<18$ & 8 \\
\hline MaxTemp & Ilev-Imat, Iflo-Imat, Idrp-Imat, Iflo-Idrp & Avg, Max & \# days MaxTemp > 28 & 12 \\
\hline Swfac & Ilev-Imat, Iflo-Imat, Idrp-Imat, Iflo-Idrp & Avg, Min & $\#$ days Swfac $<0.6$ & 12 \\
\hline Inn & Ilev-Imat, Iflo-Imat, Idrp-Imat, Iflo-Idrp & Avg, Min & $\#$ days $\operatorname{Inn}<0.6$ & 12 \\
\hline
\end{tabular}

Table 2. Preprocessed variables from Multidisciplinary Simulator for Standard Crops (STICS). STICS variables were preprocessed by crop phenology stages (Ilev: emergence, Idrp: grain filling onset, Iflo: flowering, Imat: physiological maturity), descriptive values (Cum: cumulative, Max: maximum, Avg: average) and thresholds (MinTemp, MaxTemp, Swfac and Inn). Last column (Var) corresponds to number of variables processed from a STICS, phenology stages, descriptive values and thresholds. Table A2 (Appendix A) lists all of the preprocessed variables.

227 In order to create an interpretable soybean yield model with a minimum number of variables, 228 we applied feature selection techniques to previous dataset based on three approaches: filter, embedded and wrapper.

\section{Feature selection techniques}

Feature selection is the process (automatic or manual) of selecting a subset of relevant variables which contribute most to learner (Corrales et al., 2018). Feature selection techniques can be grouped in three categories:

- Filter methods are based only on the intrinsic properties of the data (Solorio-Fernández et al., 2020). Filter method computes an importance value between one independent variable and the dependent variable. Variables with highest importance values are selected based on user criteria. Filter methods are usually computationally less expensive than embedded and wrapper methods. We used classical feature selection 
methods based on Pearson (Pearson, 1920) and Spearman (Spearman, 1961) coefficients and Information Gain (Shannon, 1948). In order to explain the statistical coefficients, independent variable is named $\mathrm{X}$ and dependent variable $\mathrm{Y}$.

- Pearson coefficient measures the linear correlation between two variables. If both variables are linearly dependent, then their correlation coefficient is close to \pm 1 . If the variables are uncorrelated, the correlation coefficient is 0 (Pearson, 1920). When Pearson coefficient is used as filter method only positive values are considered following the equation (1):

$$
r=\left|\frac{\sum_{i=1}^{n} \operatorname{cov}\left(x_{i}, y_{i}\right)}{\sum_{i=1}^{n} \sigma x_{i} \sigma y_{i}}\right|
$$

Where $x_{i}$ and $y_{i}$ are the $\mathrm{i}^{\text {th }}$ observations of independent and dependent variable respectively; $\operatorname{cov}$ corresponds to covariance and $\sigma$ indicates the standard deviation of $x$ and $y$.

- Spearman coefficient through a monotonic function measures the correlation between two variables (Spearman, 1961). A monotonic function is defined as function which is either entirely increasing or decreasing. It is similar to Pearson coefficient except that it operates on the ranks of the data rather than the raw data (Gauthier, 2001). The Spearman correlation rank is defined by equation (2):

$$
\rho=1-\frac{6 \sum_{i=1}^{n} d_{i}^{2}}{n\left(n^{2}-1\right)}
$$

Where $d_{i}$ is the difference between ranks for each $x_{i}, y_{i}$ data pair and $n$ is the number of data pairs.

- Entropy-based information gain discretizes the independent variable and subsequently the entropy is computed between $x$ and continuous $y$ variable (Yang et al., 2010) by equation (3):

$$
\text { InfoGain }=H(y)+H(x)-H(y, x)
$$

Where $H(x)$ and $H(y)$ correspond to Shannon's Entropy for $x$ and $y$ variables. $H(y, x)$ is a joint Shannon's Entropy for a variable $y$ with a condition to $x$. Detailed explanation of Shannon's Entropy is explained in (Shannon, 1948).

- Embedded methods integrate the variables selection as part of training process into learner (Guyon \& Elisseeff, 2003). We used as embedded methods the learners Random Forest (Breiman, 2001), M5 decision tree (Quinlan, 1992) and Least Absolute Shrinkage and Selection Operator (Tibshirani, 1996).

- Wrapper methods selects a subset of variables according to performance criteria (regression tasks, measure of errors as mean absolute error, mean square error, root square mean error; classification tasks measures as accuracy, precision, overall, recall, 
etc.) of a learner (Guyon \& Elisseeff, 2003). In this paper, we use the method Recursive Feature Elimination (Guyon et al., 2002).

\section{Regression learners}

In order to predict soybean yield in southern France crops, we used regression learners from different families of algorithms. They are explained briefly below.

- Linear regression (LR) explains the relationship between dependent variable and one or more independent variables by fitting a linear equation to observed data (Prion \& Haerling, 2020). Coefficients multiply the values of dependent values; the coefficient signs represent the direction of the relationship between a dependent variable and the independent variable.

- Support vector regression (SVR) is based on same principles as Support Vector Machine (Vapnik, 1995). SVR determines a regression function in the feature space considering only data points within the decision boundary lines called support vectors. In nonlinear data, a kernel function is used in order to transform the feature space into a linear hyperplane (Brereton \& Lloyd, 2010).

- Back propagation neural network (BPNN) calculates the gradient of the error function with respect to the weights of the neural network (Rumelhart et al., 1986). The computed error is propagated in a backward manner from one layer to the other until the minimum Mean Squared Error (MSE) is attained and weights can be modified accordingly (Deshwal et al., 2020).

In addition, we used each of Random forest, Least Absolute Shrinkage and Selection Operator and M5 decision tree as both an embedded method and a wrapper.

- Random forest (RF) builds several decision trees using a different bootstrap sample of data training set (Breiman, 2001). The decision trees are built using CART learner (Breiman et al., 1984). In regression tasks, RF final prediction is obtained by averaging the results of all the CART trees.

- Least Absolute Shrinkage and Selection Operator (LASSO) is a linear regression method which imposes a bound on the $\mathrm{L}_{1}$-norm of the regression coefficients, resulting in coefficient shrinkage (Tibshirani, 1996). LASSO adds a L1 penalty equal to the absolute value of the magnitude of coefficients (Equation 1). Variables are discarded when the coefficients take values equal to zero. Larger penalties are expressed by coefficient values closer to zero. The objective function for finding the minimum is shown by Equation (4):

$$
\text { minimize } \beta_{0}, \beta\left(\frac{1}{2 N} \sum_{i=1}^{N}\left(y_{i}-\beta_{0}-x_{i}^{T} \beta\right)^{2}+\lambda \sum_{j=1}^{p}\left|\beta_{j}\right|\right)
$$

Where $N$ is the total number of observations, $\lambda$ is a nonnegative regularization parameter corresponding to one value of Lambda, $y_{i}$ is the dependent variable, $p$ is the 
number of independent variables $x_{i}=\left(x_{i 1}, \ldots, x_{i p}\right)^{T}, \beta_{0}$ is the intercept, and $\beta_{j}$ are the coefficients (Shi et al., 2020).

- M5 is a conventional decision tree composed by different nodes such as root, intermediates and leaves (Quinlan, 1992). Root and intermediate nodes are chosen over the dependent variable that maximizes the expected error reduction as a function of the standard deviation of output parameter (Wang \& Witten, 1996). Leaves nodes predict the dependent variable through linear regression functions; they are fitted from data that follows one branch between root and leaf node.

\section{3- Results}

329

330

331

332

333

334

335

336

337

338

339

340

341

342

343

344

This section reports the subset of variables selected by feature selection methods and the evaluation of soybean yield models built from selected variables.

\subsection{Feature selection}

\subsubsection{Filter methods}

Filter methods were computed through R 'mlr' package (Bischl et al., 2016). With aim to create simple models with great explanatory predictive power with a minimum number of features, we defined two criteria to select the variables: (i) top-15 of variables with highest importance values for each filter method; (ii) variables selection by threshold based on importance values of top-15. Regarding to Pearson and Spearman coefficients, we selected the features with importance value greater than or equal to 0.6. Concerning to entropy-based information gain, we selected the features with importance value greater than or equal to 0.4 . We defined these thresholds following the "conventional interpretation of the correlation coefficients" proposed in (Schober et al., 2018). Values between 0.60 - 0.79 are defined as "moderately correlated" and coefficient values between $0.70-0.89$ are interpreted as "strongly correlated". Table 3 shows Top-15 of soybean variables selected by filter methods (Appendix B contains the entire ranking).

\begin{tabular}{|c|c|c|c|c|c|c|}
\hline \multirow[t]{2}{*}{ Pos } & \multicolumn{2}{|c|}{ Pearson coefficient } & \multicolumn{2}{|c|}{ Spearman coefficient } & \multicolumn{2}{|c|}{ Entropy-based information gain } \\
\hline & Variable & Importance & Variable & Importance & Variable & Importance \\
\hline 1 & Masec(n)_Imat & 0.7923 & Lai(n)_Imat & 0.7699 & Lai(n)_Imat & 0.5929 \\
\hline 2 & Lai(n)_Imat & 0.7726 & Masec(n)_Imat & 0.7311 & Masec(n)_Imat & 0.5875 \\
\hline 3 & Qnplante_Idrp & 0.7710 & Qnplante_Idrp & 0.7137 & Qnplante_Imat & 0.5515 \\
\hline 4 & Qnplante_Imat & 0.7523 & Masec(n)_Idrp & 0.7003 & Ep_cum_Idrp-Imat & 0.4223 \\
\hline 5 & Masec(n)_Idrp & 0.7334 & Ep_cum_Iflo-Imat & 0.6886 & Qfix_Imat & 0.4072 \\
\hline 6 & Ep_cum_Idrp-Imat & 0.6819 & Ep_cum_Idrp-Imat & 0.6734 & Inn_min_Iflo-Idrp & 0.3799 \\
\hline 7 & Qfix_Imat & 0.6805 & Qnplante_Imat & 0.6714 & Inn_avg_Iflo-Idrp & 0.3652 \\
\hline 8 & Ep_cum_Iflo-Imat & 0.6650 & Ep_cum_Ilev-Imat & 0.6456 & Ep_cum_Iflo-Imat & 0.3486 \\
\hline 9 & Raint_cum_Idrp-Imat & 0.6326 & Lai(n)_Idrp & 0.6439 & $\begin{array}{l}\text { Days_Swfac_0.6_Iflo- } \\
\text { Imat }\end{array}$ & 0.3443 \\
\hline 10 & Lai(n)_Idrp & 0.6292 & Raint_cum_Idrp-Imat & 0.6288 & Inn_avg_Ilev-Imat & 0.3400 \\
\hline 11 & AvgTemp_avg_Idrp-Imat & 0.6157 & Swfac_min_Idrp-Imat & 0.6160 & Inn_avg_Iflo-Imat & 0.3380 \\
\hline 12 & Swfac_avg_Iflo-Imat & 0.6088 & Swfac_min_Iflo-Imat & 0.6136 & Masec(n)_Idrp & 0.3300 \\
\hline 13 & MinTemp_avg_Idrp-Imat & 0.5937 & $\begin{array}{l}\text { AvgTemp_avg_Idrp- } \\
\text { Imat }\end{array}$ & 0.6081 & Qnplante_Idrp & 0.3285 \\
\hline 14 & Ep_cum_Ilev-Imat & 0.5842 & Swfac_min_Ilev-Imat & 0.6009 & Raint_cum_Idrp-Imat & 0.3080 \\
\hline 15 & $\begin{array}{l}\text { Days_Swfac_0.6_Iflo- } \\
\text { Imat }\end{array}$ & 0.5811 & $\begin{array}{l}\text { MinTemp_avg_Idrp- } \\
\text { Imat }\end{array}$ & 0.5977 & $\begin{array}{l}\text { Days_Swfac_0.6_Iflo- } \\
\text { Idrp }\end{array}$ & 0.3025 \\
\hline
\end{tabular}


In this sense, 12 and 14 variables were selected by Pearson and Spearman respectively. The variables Lai(n)_Imat,Masec(n)_Imat, Qnplante_Imat,EP_cum_Idrp-Imat and Qfix_Imat were selected by entropy-based information gain. The subdatasets with the selected variables by filter methods were used to train the regression learners presented in Section 2. Besides, RF, LASSO and M5 decision tree act as regression learners and feature selection techniques due these learners are considered embedded methods. In other words, RF, LASSO and M5 are trained with subset of variables selected by filter methods and subsequently the embedded methods/learners select a new subset of variables in the training process into learner. The results are presented in Table 5.

\subsubsection{Embedded methods}

We used as embedded methods the learners: Random forest, Least Absolute Shrinkage and Selection Operator and M5 decision tree. The variable selection process for each one is explained below.

\section{Random Forest}

Random Forest (RF) gathers a set of CART trees in order to obtain the soybean yield prediction by averaging the results of all of trees. We used R packages 'randomForest' to create RF model and 'randomForestExplainer' (Liaw \& Wiener, 2002) to design multi-way plot shown in Figure 3. Five hundred CART trees were built (ntree parameter) as result, 42 variables were sampled as candidates at each split. The multi-way plot focuses on three importance measures that derive from the structure of trees in the forest: (i) the mean_min_depth variable refers to the depth of first split on the variable to the top of the tree; (ii) the times_a_root variable measures the number of times a variable is set as top of a decision tree. Figure 3 presents multi-way plot for first 15 relevant variables.

Lai(n)_Imat was the most used variable as top split criterion (148 times) followed by Masec(n)_Imat (67 times) and Ep_cum_Iflo-Imat (58 times). Variables as Qfix_Iflo and Precip_cum_Idrp-Imat were never used as top of decision trees and they have the longest distance (mean minimum depth of 6.728 and 6.398 respectively) to the top of decision trees considered less associated with the dependent variable Mafruit. Other variables as Qfix_Idrp, Lai(n)_Iflo and Precip_cum_Iflo-Idrp can be considered as intermediate nodes of the trees (times_a_root $=0$ ) with mean minimum depth less than Precip_cum_Idrp-Imat and Qfix_Iflo (mean_min_depth $=4.856,5.045$ and 5.297 respectively). 


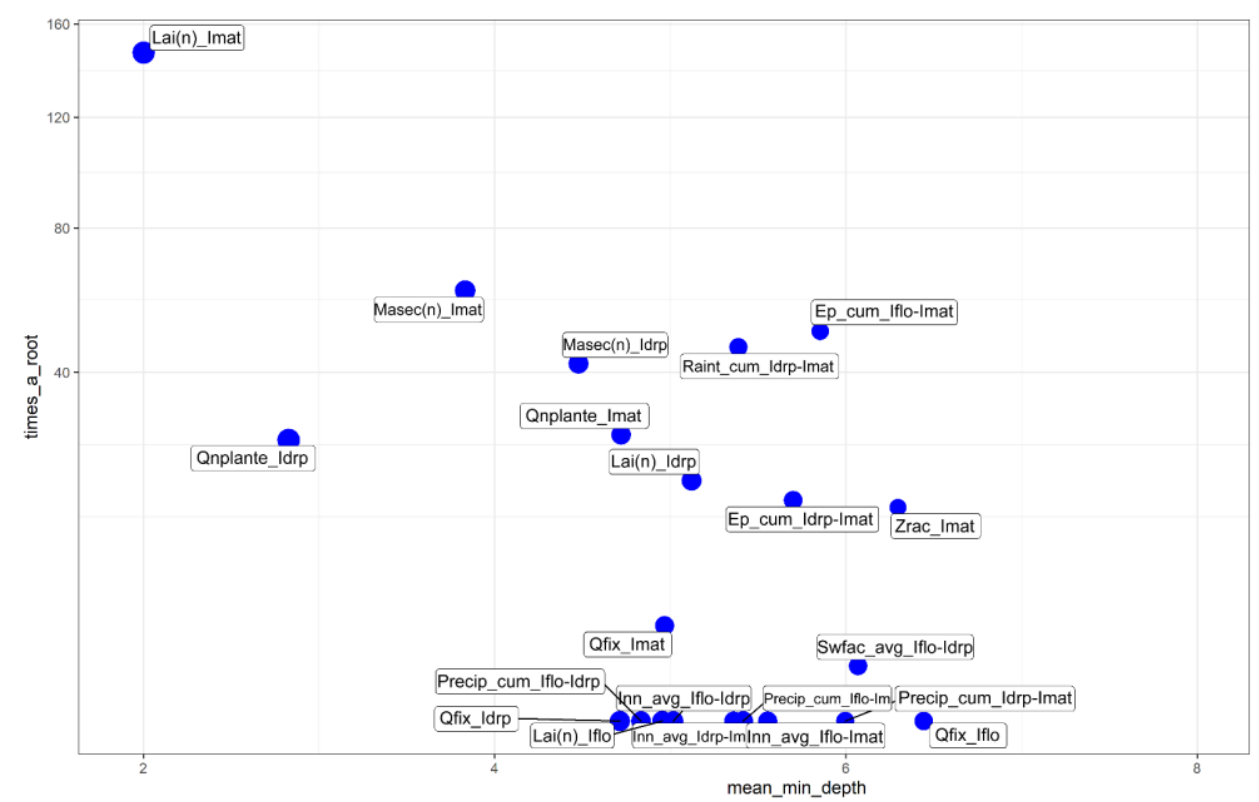

Figure 3. Multi-way plot between two measures of importance: mean_min_depth (x-axis) and times_a_root (y-axis). First 15 relevant variables are depicted. $\mathrm{X}$-axis correspond to mean depth of first split on the variable, $\mathrm{y}$-axis the number of trees in which the root is split on the variable.

\section{Least Absolute Shrinkage and Selection Operator}

We used the R package 'caret' to build LASSO model (Kuhn, 2008). Root Mean Square Error (RMSE) was used to select the optimal model using the smallest value. LASSO model was run with parameters fraction $=0.1$ and lambda $=0.01$ (Equation 1$)$. The LASSO model set the regression coefficients of 21 variables to zero by imposing the $\mathrm{L} 1$ penalty. Table $\mathrm{C} 1$ (Appendix C) contains the regression coefficients of 66 variables calculated by LASSO.

\section{M5 decision tree}

M5 was built by R package 'RWeka' (Hornik et al., 2009). The construction of M5 tree is based on recursive splitting of the standard deviation of Mafruit (dependent variable) that reach a node as a measure of the error at the node. The variable that maximizes the expected error reduction is selected for splitting at the node. The expected reduction of the error is obtained as a result of testing each variable at that node. To remove the problem of over fitting, M5 uses a method to prune back the over grown tree. Figure 4 shows the structure of the pruned M5 tree to predict the soybean yield (Mafruit) regarding the thirteen selected variables (Table 4). Left branches show conditions below the node threshold, for example, if the top node Lai $(n)$ Imat $\leq 1.103$ and if Inn_avg_Iflo-Idrp $\leq 0.769$, the linear model LM 1 must be selected. Thirty-seven nodes were created including nineteen linear models as decision rules. We defined 3 observations as minimum number at the leaf node. Appendix C contains the linear models generated by M5. 


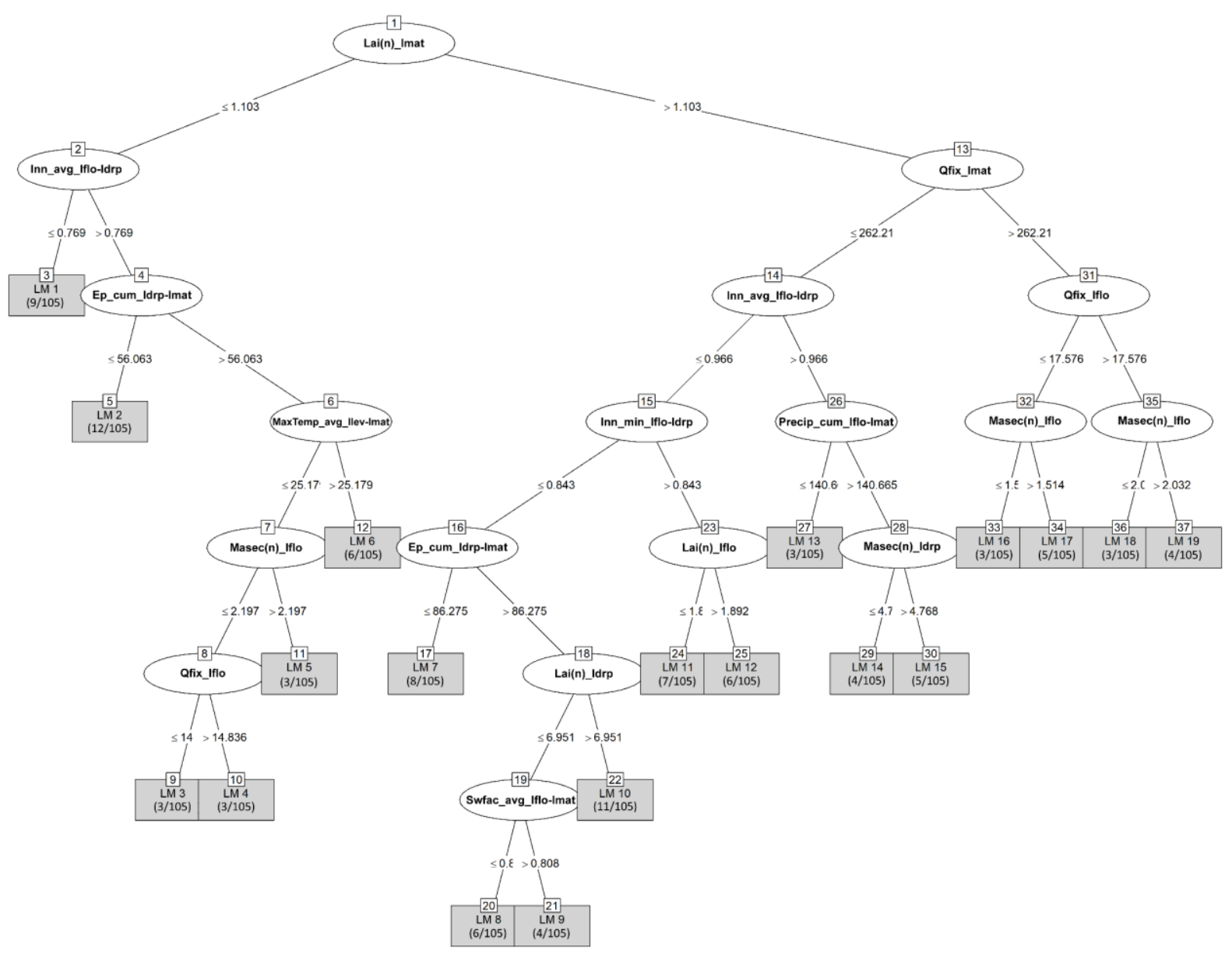

400

401

402

403

404

405

406

407

408

409

410

411

412

413

414

415

Figure 4. M5 pruned decision tree. Thirteen variables were selected and 19 decision rules (linear regressions) were created. At the leaf node, the number in parenthesis corresponds to observations for each linear regression.

\subsubsection{Wrapper methods}

A greedy algorithm named Recursive Feature Elimination (RFE) was used as wrapper method (Kohavi \& John, 1997; Guyon et al., 2002). RFE selects a subset of variables to improve a learner performance by removing the least important features. This process is repeated recursively (based on backward elimination) until the optimal number of features is obtained. The recursive step plays a key role due the relative importance of each variable can change substantially over a different subset of variables during the backward elimination process (particularly for highly correlated variables) (Granitto et al., 2006). We used the RFE version coded in R package 'caret' (Kuhn, 2008). Six learners were selected (explained in section 2) to determine the performance of subsets of variables selected by RFE shown in Table 4 . The variables subset selection were conducted through lowest Mean Absolute Error obtained by learners. Recursive Feature Elimination selected all of the variables for RF model. The variables subset for remaining models are less than 17.

\begin{tabular}{|l|l|c|c|}
\hline Learner & \multicolumn{1}{|c|}{ Variables } & $\begin{array}{c}\text { Selected } \\
\text { variables }\end{array}$ & RMSE \\
\hline LR & $\begin{array}{l}\text { MaxTemp_avg_Idrp-Imat, Qnplante_Idrp, Masec(n)_Imat, } \\
\text { Ep_cum_Idrp-Imat,Lai(n)_Imat, Raint_cum_Idrp-Imat }\end{array}$ & 6 & 0.5865 \\
\hline SVR & $\begin{array}{l}\text { Lai(n)_Imat, Masec(n)_Imat, Qnplante_Idrp, Qnplante_Imat, } \\
\text { Masec(n)_Idrp, Ep_cum_Iflo-Imat,_Ep_cum_Idrp-Imat, },\end{array}$ & 14 & 0.6750 \\
\hline
\end{tabular}




\begin{tabular}{|c|c|c|c|}
\hline & $\begin{array}{l}\text { Ep_cum_Ilev-Imat, Qfix_Imat, } \quad \text { Zrac_Imat, } \quad \text { Zrac_Idrp, } \\
\text { Lai(n)_Idrp, Raint_cum_Idrp-Imat, MaxTemp_avg_Idrp-Imat }\end{array}$ & & \\
\hline BPNN & $\begin{array}{l}\text { Lai(n)_Imat, Masec(n)_Imat, Qnplante_Idrp, Qnplante_Imat, } \\
\text { Masec(n)_Idrp, Ep_cum_Iflo-Imat, Ep_cum_Idrp-Imat, } \\
\text { Qfix_Imat, Zrac_Imat, Zrac_Idrp, Ep_cum_Ilev-Imat, } \\
\text { Lai(n)_Idrp, Raint_cum_Idrp-Imat, MaxTemp_avg_Idrp-Imat, } \\
\text { Swfac_min_Ilev-Imat, Swfac_min_Iflo-Imat }\end{array}$ & 16 & 1.294 \\
\hline $\mathrm{RF}$ & All variables were selected & 87 & 0.4639 \\
\hline LASSO & $\begin{array}{l}\text { Lai(n)_Imat, Masec(n)_Imat, Qnplante_Idrp, Qnplante_Imat, } \\
\text { Masec(n)_Idrp, Ep_cum_Iflo-Imat, Ep_cum_Idrp-Imat, } \\
\text { Qfix_Imat, Ep_cum_Ilev-Imat, Zrac_Idrp, Zrac_Imat, } \\
\text { Raint_cum_Idrp-Imat, Lai(n)_Idrp, MinTemp_avg_Idrp-Imat, } \\
\text { MaxTemp_avg_Idrp-Imat,Swfac_min_Iflo-Imat }\end{array}$ & 16 & $6.141 \mathrm{e}-01$ \\
\hline M5 & 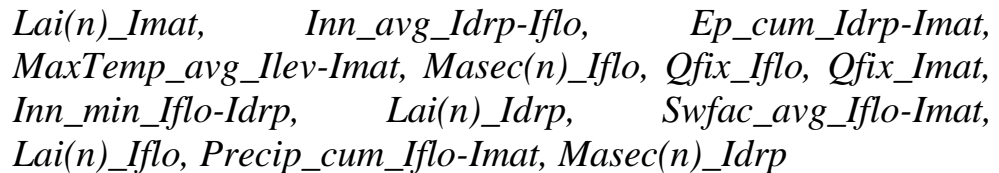 & 13 & 0.5465 \\
\hline
\end{tabular}

Table 4. Subset of variables selected by Recursive Feature Elimination (RFE) and base learners: Linear Regression (LR), Support Vector Regression (SVR), M5 decision tree, Random Forest (RF) and Backpropagation Neural Network (BPNN). Learner performance is based on Root Mean Square Error (RMSE).

Concerning time complexity, RFE is slower than filter and embedded methods, since RFE needs to evaluate performance criteria for each iteration besides the computational cost of the model training. In this sense, learners based on linear models as LR and LASSO obtained much less computational cost (59.42 and 137.53 seconds) than BPNN, RF and M5 (1421.25, 1268.27 and 1033.52 seconds). In contrast to Support Vector Regression which imposed considerable computational cost (5271.56 seconds) due to margin maximization to find the support vectors and nonlinear transformations of the feature space (Yu et al., 2003). Figure 5 presents the time complexity of the variables subset selection by Recursive Feature Elimination and base learners. Wrapper methods were run on Windows 10 comprised of Intel Core i5-774HQ CPU $2.80 \mathrm{GHz}-16 \mathrm{~GB}$ RAM based on sequential computing.

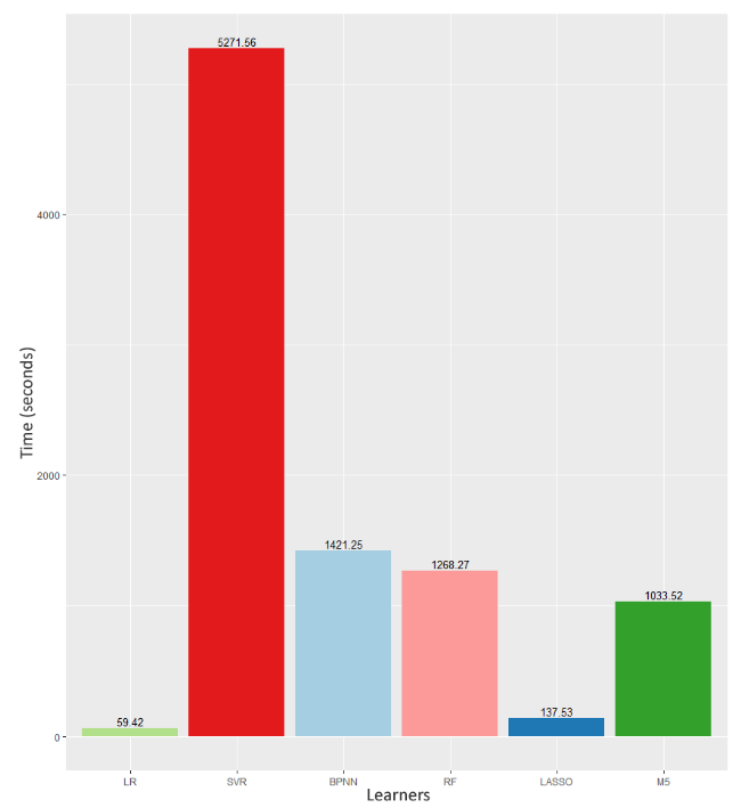

Figure 5. Time complexity to select subset of variables by Recursive Feature Elimination (RFE) and base learners: Linear Regression (LR), Support Vector Regression (SVR), M5 decision tree, Random Forest (RF) and Backpropagation Neural Network (BPNN). 
In order to examine the performance of subset of variables selected by feature selection methods, we used traditional statistical criteria to estimate the prediction accuracy of regression learners as Coefficient of determination $\left(\mathrm{R}^{2}\right)$, Mean Square Error (MSE), Root Mean Square Error (RMSE) and Mean Absolute Error (MAE). The metric $\mathrm{R}^{2}$ was adopted to measure the correlation of the observed and predicted values.

Regression learners were trained with 105 observations and evaluated with 122 examples (explained in section 2). Table 5 presents the results of regression learners trained with subset of variables selected by feature selection methods. The underlined values correspond to statistical criteria obtained by best two learners and feature selection method.

\begin{tabular}{|c|c|c|c|c|c|c|c|c|}
\hline \multirow{2}{*}{$\begin{array}{c}\text { Feature } \\
\text { selection } \\
\text { approach }\end{array}$} & \multirow{2}{*}{$\begin{array}{c}\text { Feature } \\
\text { selection } \\
\text { method }\end{array}$} & \multirow[b]{2}{*}{ SC } & \multicolumn{6}{|c|}{ Learners } \\
\hline & & & LR & SVR & BPNN & $\mathbf{R F}$ & LASSO & M5 \\
\hline \multirow{15}{*}{ Filter } & \multirow{5}{*}{$\begin{array}{l}\text { Pearson } \\
\text { correlation }\end{array}$} & $\mathbf{R}^{2}$ & 0.6185 & 0.6389 & 0.1837 & 0.3487 & 0.6274 & 0.6193 \\
\hline & & MSE & 0.9085 & 0.6539 & 2.1301 & 1.0325 & 0.7250 & 0.9211 \\
\hline & & RMSE & 0.9531 & 0.8086 & 1.4595 & 1.0161 & 0.8514 & 0.9597 \\
\hline & & MAE & 0.7227 & 0.6267 & 1.2375 & 0.8422 & 0.6552 & 0.7258 \\
\hline & & $\begin{array}{l}\text { No. Selected } \\
\text { Variables }\end{array}$ & 12 & 12 & 12 & 12 & 12 & 12 \\
\hline & \multirow{5}{*}{$\begin{array}{l}\text { Spearman } \\
\text { correlation }\end{array}$} & $\mathbf{R}^{2}$ & 0.5890 & 0.6394 & 0.1841 & 0.3463 & 0.6101 & 0.6276 \\
\hline & & MSE & 1.0418 & 0.6948 & 1.4388 & 1.0818 & 0.8167 & 0.6776 \\
\hline & & RMSE & 1.0207 & 0.8335 & 1.1995 & 1.0401 & 0.9037 & 0.8231 \\
\hline & & MAE & 0.7889 & 0.6551 & 1.0158 & 0.8505 & 0.6862 & 0.6397 \\
\hline & & $\begin{array}{l}\text { No. Selected } \\
\text { Variables }\end{array}$ & 14 & 14 & 14 & 14 & 14 & 14 \\
\hline & \multirow{5}{*}{$\begin{array}{l}\text { Entropy-based } \\
\text { information } \\
\text { gain }\end{array}$} & $\mathbf{R}^{2}$ & 0.3974 & 0.3916 & 0.2701 & 0.2622 & 0.3961 & 0.2502 \\
\hline & & MSE & 0.9479 & 1.0085 & 4.0698 & 1.1859 & 0.9554 & 1.2713 \\
\hline & & RMSE & 0.9736 & 1.0042 & 2.0173 & 1.0890 & 0.9774 & 1.1275 \\
\hline & & MAE & 0.7951 & 0.8215 & 1.7373 & 0.8815 & 0.7975 & 0.9212 \\
\hline & & $\begin{array}{l}\text { No. Selected } \\
\text { Variables }\end{array}$ & 5 & 5 & 5 & 5 & 5 & 5 \\
\hline \multirow{5}{*}{ Embedded } & \multirow{5}{*}{$\begin{array}{l}\text { Learners: } \\
\text { RF, LASSO } \\
\text { and M5 }\end{array}$} & $\mathbf{R}^{2}$ & - & - & - & 0.5020 & 0.1249 & 0.4010 \\
\hline & & MSE & - & - & - & 0.8300 & 6.1841 & 0.9466 \\
\hline & & RMSE & - & - & - & 0.9110 & 2.4867 & 0.9729 \\
\hline & & MAE & - & - & - & 0.7258 & 1.9206 & 0.7802 \\
\hline & & $\begin{array}{l}\text { No. Selected } \\
\text { Variables }\end{array}$ & - & - & - & 42 & 66 & 87 \\
\hline \multirow{5}{*}{ Wrapper } & \multirow{5}{*}{$\begin{array}{c}\text { Recursive } \\
\text { Feature } \\
\text { Elimination } \\
(\text { RFE })\end{array}$} & $\mathbf{R}^{2}$ & 0.6912 & 0.7102 & 0.1829 & 0.5020 & 0.6718 & 0.4010 \\
\hline & & MSE & $\overline{0.4807}$ & $\overline{0.4170}$ & 1.4916 & 0.8300 & 0.4760 & 0.9466 \\
\hline & & RMSE & $\overline{0.6933}$ & 0.6458 & 1.2213 & 0.9110 & 0.6899 & 0.9729 \\
\hline & & MAE & 0.5469 & 0.5230 & 0.9746 & 0.7258 & 0.5747 & 0.7802 \\
\hline & & $\begin{array}{l}\text { No. Selected } \\
\text { Variables }\end{array}$ & 6 & 14 & 16 & 87 & 16 & 13 \\
\hline
\end{tabular}

Table 5. Results of regression learners trained with subset of variables selected by feature selection methods. Validation dataset (Section 2) was used to evaluate the regression learners. Statistical criteria (SC) used to estimate the performance of regression learners: Coefficient of determination (R2), Mean Square Error (MSE), Root Mean Square Error (RMSE) and Mean Absolute Error (MAE). The underlined values correspond to statistical criteria obtained by best two learners and feature selection method.

According to filter methods, Pearson, Spearman and Entropy coefficients selected 12, 14 and 5 variables respectively (Section 3). The regression learners LR, SVR and BPNN were trained with subset of variables selected by filter methods; SVR obtained the best results with subset of feature selected by Pearson coefficient $\left(\mathrm{R}^{2}=0.6389\right.$, MSE $=0.6539$, $\mathrm{RMSE}=0.8086$ and MAE $=0.6267)$. Regression learners RF, LASSO and M5 decision tree act as ensemble 
approaches for feature selection due these learners are considered embedded methods as well. In other words, embedded methods were trained with subset of variables selected by filter methods. Subsequently, embedded methods select a new subset of variables in the training process into learner. However, the ensemble of filter and embedded methods do not improve the performance obtained by SVR trained with subset of variables chosen by Pearson coefficient.

The number of variables selected by two embedded methods were higher respecting to others feature selection approaches. Random Forest and LASSO selected 87 and 66 variables respectively, whereas M5 decision Tree 13 variables (Section 3). Random Forest reached the best performance in the ensemble methods $\left(\mathrm{R}^{2}=0.5020, \mathrm{MSE}=0.8300, \mathrm{RMSE}=0.9110\right.$ and MAE $=0.7258$ ), however RF does not overcome the performance obtained by SVR and Pearson coefficient in the filter methods.

Concerning to wrapper method, Recursive Feature Elimination selected 6, 14 and 16 variables for LR, SVR and BPNN. SVR achieved the best results compared to all of combination of feature selection approaches and learners $\left(R^{2}=0.7102, \mathrm{MSE}=0.4170, \mathrm{RMSE}=0.6458\right.$ and MAE $=0.5230$ ). Remain of learners that work as ensemble feature selection among wrapper and embedded methods (RF, LASSO and M5 decision tree), RFE proposes different subset of variables created in the backward elimination process. The embedded methods are tested with subset of variables proposed by wrapper method and they select a new subset of variables in the training process into learner. The best subset of variables are selected regarding to performance criteria of the embedded method. LASSO trained with 16 variables selected by RFE (Table 4) reached the best results $\left(\mathrm{R}^{2}=0.6718, \mathrm{MSE}=0.4760, \mathrm{RMSE}=0.6899\right.$ and MAE $=0.5747)$ compared to RF and M5 of the wrapper method. Besides, RFE improve the performance of LASSO compared to LASSO's version of filter and embedded.

In summary, the wrapper methods RFE-SVR $\left(\mathrm{R}^{2}=0.7102, \mathrm{MSE}=0.4170, \mathrm{RMSE}=0.6458\right.$ and MAE $=0.5230)$ and RFE-LR $\left(\mathrm{R}^{2}=0.6912, \mathrm{MSE}=0.4807, \mathrm{RMSE}=0.6933\right.$ and MAE $=0.5469$ ) achieved the best results from validation dataset. Figure 6 depicts the scatter plots of observed vs simulated soybean yield values by RFE-SVR and RFE-LR.

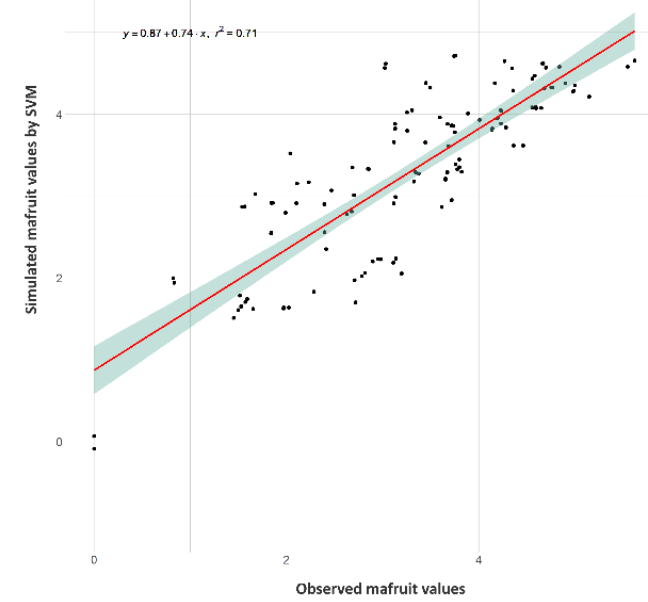

a. Observed Mafruit values vs Simulated Mafruit values by RFE-SVR

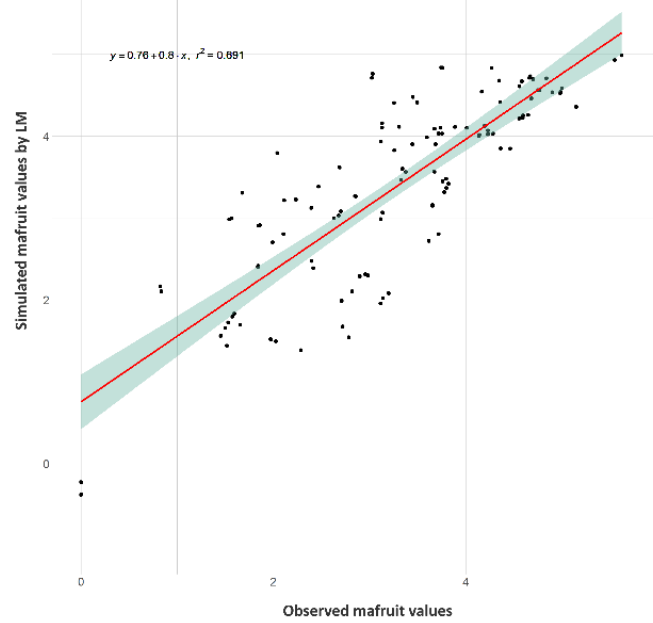

b. Observed Mafruit values vs Simulated Mafruit values by RFE-LR 
For real values of soybean yield equal to zero, RFE-SVR and RFE-LR predict negative soybean values or close to zero. RFE-SVR simulates Mafruit values equal to $0.066,-0.086$ and -0.085 for 3 observations where Mafruit $=0$ of the validation dataset (Béziers in 2011 with maturity group I in varieties Isidor, Santana and maturity group II in Ecudor variety). Similarly, LR-RFE predicts $-0.227,-0.379$ and -0.378 for same observations of validation dataset.

\subsection{Comparative study}

In order to demonstrate the performance of RFE-SVR and RFE-LR, we compared both regression models against STICS simulations developed in (Schoving, 2020). The soybean yield model proposed by Schoving was calibrated with the same training set as presented in section 2. Table 6 shows the results of RFE-SVR, RFE-LR and STICS models evaluated from validation dataset (Section 2).

\begin{tabular}{|l|c|c|}
\hline \multirow{2}{*}{ Models } & \multicolumn{2}{|c|}{ Statistical criteria } \\
\cline { 2 - 3 } & $\mathbf{R}^{\mathbf{2}}$ & RMSE \\
\hline RFE-SVR & 0.710 & 0.645 \\
\hline RFE-LR & 0.691 & 0.693 \\
\hline (Schoving, 2020) & 0.040 & 1.320 \\
\hline
\end{tabular}

Table 6. Comparison of Support Vector Regression and Linear Regression (LR) trained with subset of variables selected by Recursive Feature Selection (RFS) vs soybean yield model proposed by (Schoving, 2020). Validation dataset (Section 2) was used to evaluate the models. Statistical criteria used to estimate the performance of models: Coefficient of determination $\left(\mathrm{R}^{2}\right)$ and Root Mean Square Error (RMSE).

The two regression models explained around $70 \%$ of the grain yield variation and they achieved half of RMSE values obtained for STICS simulations developed in (Schoving, 2020). Although total aboveground biomass was correctly simulated by (Schoving, 2020) $\left(r^{2}=0.64\right)$, final grain yield of semi-indeterminate and indeterminate soybean cultivars was poorly represented (Table $\left.6 ; \mathrm{r}^{2}=0.04\right)$. This is probably because STICS uses the standard formalism of wheat and maize crops to simulate the final grain yield in soybean.

\section{4- Discussion}

Feature selection methods are relevant in order to reduce the computational complexity and improve the model generalization ability (Maldonado \& Weber, 2009). High dimensional variables impose a high computational cost and a high cost of data acquisition. On the other hand, a low-dimensional representation reduces the risk of overfitting (Famili et al., 1997; Liu $\&$ Zheng, 2006). The value added by applying feature selection techniques is to determinate a subset of available variables to build a good model, which is a combinatorial problem in the number of original variables (Wolsey \& Nemhauser, 1999; Guyon \& Elisseeff, 2003).

With this rationale, we used popular filter, embedded and wrapper methods in order to select the relevant variables to predict soybean yield.

Filter methods are independent of any learners and they are based on performance evaluation metrics calculated directly from the data. We used two correlation-based filters (Pearson and Spearman) followed by a measure based on information theory (Information Gain). Figure 7 presents Venus diagram of top- 15 variables selected by filter methods. Correlation-based filters selected twelve same variables. The correlations found by Pearson and Spearman are equivalent to rank the common twelve variables; whereas Pearson inspects straight connections, Spearman evaluates monotonic connections (regardless of whether direct or not) (Thirumalai et al., 2017). However, of the three filter methods share less features in common (eight variables) due to 
entropy-based information is designed to observe the amount of information gained between two discrete variables, and dataset used contains only numeric variables.

The principle of embedded methods (feature selection as part of the training process) is to reduce the computation time taken up for testing several subsets of variables which is done in wrapper methods (Chandrashekar \& Sahin, 2014). In this work, the number of variables selected by RF and LASSO were higher. LASSO selected 66 variables and Random Forest all of the initial variable set. Although M5 decision Tree selected less variables (13), the results were worse than $\mathrm{RF}\left(\mathrm{R}^{2}=0.4010, \mathrm{MSE}=0.9466, \mathrm{RMSE}=0.9729\right.$ and MAE =0. 7802). Embedded methods showed an improvement when they were used as ensemble approaches of filter and wrapper techniques.

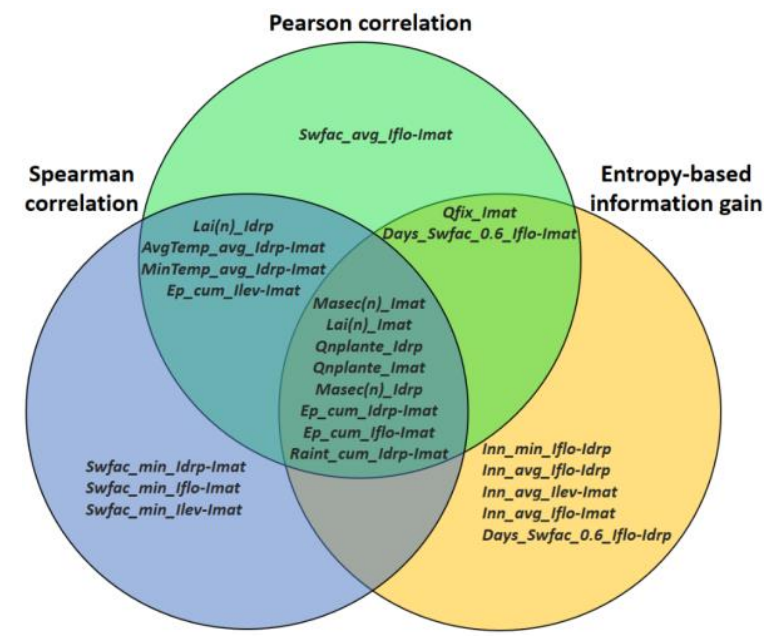

Figure 7.Venus diagram of top-15 variables selected by filter methods: Pearson, Spearman and Entropy-based information

Wrapper methods are widely recognized and considered a superior alternative for two reasons: (i) they evaluate variables iteratively with respect to performance learner. Therefore, variables selected by wrapper approach are more likely to suit the learner (Kohavi \& John, 1997); (ii) wrapper approaches evaluate variables jointly and are effective in capturing intrinsic relationships such as interactions among multiple variables (Freitas, 2001). However computational cost is high, even for learners that exhibit a moderate complexity, the number of iterations required by the search of subset variables is high, especially as more complex search strategies are used (Talavera, 2005). In this paper, we used a dataset with few observations (105 instances) but it contains a large number of features (87 variables). Recursive Feature Elimination through SVR and LR learners reached the best performance. RFE-SVR and RFELR are recommended to be used as surrogate models to predict soybean yield in southern France. Concerning to time complexity, the lowest time was obtained by RFE-LR $(59.42$ seconds) against RFE-SVR (5271.56 seconds).

On the other hand, Support Vector Regression and Linear Regression belong different type of learners. SVR is considered a black-box model whereas LR an interpretable model (LoyolaGonzález, 2019). SVR builds a hyperplane or set of hyperplanes in a high-dimensional space, which are very hard to explain and to be understood by experts in practical applications (Rudin, 2019). LR generates a linear equation to explain the correlation among variables in a language close to a human expert.

In this sense, RFE-LR is represented by the following linear equation: 


$$
\begin{gathered}
\text { Mafruit }=-0.3095 * \text { MaxTemp_avg_Idrp-Imat }+0.0148 * \text { Qnplante_Idrp }+0.0057 * \text { Masec }(n) \_I m a t+ \\
0.0066 * \text { Ep_cum_Idrp-Imat }+0.0458 * \text { Lai }(n) \_I m a t+0.0008 * \text { Raint_cum_Idrp-Imat }+8.5049
\end{gathered}
$$

553

554

555

556

557

558

559

560

561

562

563

564

565

566

567

568

569

570

571

572

573

574

RFE-LR model explains biologically the higher leaf area duration during grain filling through the increase of grain yield (Mafruit) with aboveground biomass at maturity (Masec(n)_Imat), precipitation amount (Raint_cum_Idrp-Imat), cumulative crop transpiration during grain filling (Ep_cum_Idrp-Imat), the mineral nitrogen accumulated by the plants at the onset of grain filling (Qnplante_Idrp) and residual leaf area index at maturity (Lai(n)_Imat). All these variables demonstrate that radiation, water and nitrogen resources are highly representative variables of soybean grain yield. Further, the high temperatures may affect crop photosynthesis and grain filling (MaxTemp_avg_Idrp-Imat) which is in accordance with our knowledge of soybean physiology (Grassini et al., 2021).

\section{Acknowledgments}

This research was supported by Horizon 2020 SusCrop-ERA-NET Cofound on Sustainable Crop Production: LegumeGap project (2019-2021) "Increasing productivity and sustainability of European plant protein production by closing the grain legume yield gap": https://www.suscrop.eu/projects-first-call/legumegap

\section{REFERENCES}

Battisti, R., Parker, P. S., Sentelhas, P. C., \& Nendel, C. (2017). Gauging the sources of uncertainty in soybean yield simulations using the MONICA model. Agricultural Systems, 155, 9-18. https://doi.org/10.1016/j.agsy.2017.04.004

Bhatia, V. S., Singh, P., Wani, S. P., Chauhan, G. S., Rao, A. V. R. K., Mishra, A. K., \& Srinivas, K. (2008). Analysis of potential yields and yield gaps of rainfed soybean in India using CROPGROSoybean model. Agricultural and Forest Meteorology, 148(8), 1252-1265. https://doi.org/10.1016/j.agrformet.2008.03.004

Bischl, B., Lang, M., Kotthoff, L., Schiffner, J., Richter, J., Studerus, E., Casalicchio, G., \& Jones, Z. M. (2016). mlr: Machine Learning in R. The Journal of Machine Learning Research, 17(1), 59385942.

Breiman, L. (2001). Random forests. Machine Learning, 45(1), 5-32.

Breiman, L., Friedman, J. H., Olshen, R. A., \& Stone, C. J. (1984). Classification and regression trees. CERN Document Server; Wadsworth \&amp; Brooks/Cole Advanced Books \&amp; Software. https://cds.cern.ch/record/2253780 
Brereton, R. G., \& Lloyd, G. R. (2010). Support Vector Machines for classification and regression. Analyst, 135(2), 230-267. https://doi.org/10.1039/B918972F

Brisson, N., Launay, M., Mary, B., \& Beaudoin, N. (2009). Conceptual basis, formalisations and parameterization of the STICS crop model. Editions Quae.

Brisson, N., Mary, B., Ripoche, D., Jeuffroy, M. H., Ruget, F., Nicoullaud, B., Gate, P., Devienne-Barret, F., Antonioletti, R., \& Durr, C. (1998). STICS: a generic model for the simulation of crops and their water and nitrogen balances. I. Theory and parameterization applied to wheat and corn.

Casadebaig, P., Debaeke, P., \& Wallach, D. (2020). A new approach to crop model calibration: Phenotyping plus post-processing. Crop Science, 60(2), 709-720. https://doi.org/10.1002/csc2.20016

Casadebaig, P., Guilioni, L., Lecoeur, J., Christophe, A., Champolivier, L., \& Debaeke, P. (2011). SUNFLO, a model to simulate genotype-specific performance of the sunflower crop in contrasting environments. Agricultural and Forest Meteorology, 151(2), 163-178. https://doi.org/10.1016/j.agrformet.2010.09.012

Chandrashekar, G., \& Sahin, F. (2014). A survey on feature selection methods. Computers \& Electrical Engineering, 40(1), 16-28. https://doi.org/10.1016/j.compeleceng.2013.11.024

Corrales, D. C., Lasso, E., Ledezma, A., \& Corrales, J. C. (2018). Feature selection for classification tasks: Expert knowledge or traditional methods? Journal of Intelligent \& Fuzzy Systems, 34(5), 2825-2835.

Coucheney, E., Buis, S., Launay, M., Constantin, J., Mary, B., de Cortázar-Atauri, I. G., Ripoche, D., Beaudoin, N., Ruget, F., \& Andrianarisoa, K. S. (2015). Accuracy, robustness and behavior of the STICS soil-crop model for plant, water and nitrogen outputs: Evaluation over a wide range of agro-environmental conditions in France. Environmental Modelling \& Software, 64, 177-190. 
Cui, C., Hu, M., Weir, J. D., \& Wu, T. (2016). A recommendation system for meta-modeling: A metalearning based approach. Expert Systems with Applications, 46, 33-44. https://doi.org/10.1016/j.eswa.2015.10.021

Deshwal, D., Sangwan, P., \& Kumar, D. (2020). A Language Identification System using Hybrid Features and Back-Propagation Neural Network. Applied Acoustics, 164, 107289. https://doi.org/10.1016/j.apacoust.2020.107289

Eugenio, F. C., Grohs, M., Venancio, L. P., Schuh, M., Bottega, E. L., Ruoso, R., Schons, C., Mallmann, C. L., Badin, T. L., \& Fernandes, P. (2020). Estimation of soybean yield from machine learning techniques and multispectral RPAS imagery. Remote Sensing Applications: Society and Environment, 20, 100397. https://doi.org/10.1016/j.rsase.2020.100397

Falconnier, G. N., Journet, E.-P., Bedoussac, L., Vermue, A., Chlébowski, F., Beaudoin, N., \& Justes, E. (2019). Calibration and evaluation of the STICS soil-crop model for faba bean to explain variability in yield and N2 fixation. European Journal of Agronomy, 104, 63-77. https://doi.org/10.1016/j.eja.2019.01.001

Falconnier, G. N., Vermue, A., Journet, E.-P., Christina, M., Bedoussac, L., \& Justes, E. (2020). Contrasted response to climate change of winter and spring grain legumes in southwestern France. Field Crops Research, 259, 107967. https://doi.org/10.1016/j.fcr.2020.107967

Famili, A., Shen, W.-M., Weber, R., \& Simoudis, E. (1997). Data preprocessing and intelligent data analysis. Intelligent Data Analysis, 1(1), 3-23.

FAOSTAT. (2021). Food and agriculture organization of the united nations-Crops. http://www.fao.org/faostat/en/\#data/QC

Freitas, A. A. (2001). Understanding the crucial role of attribute interaction in data mining. Artificial Intelligence Review, 16(3), 177-199.

Gauthier, T. D. (2001). Detecting trends using Spearman's rank correlation coefficient. Environmental Forensics, 2(4), 359-362. 
Granitto, P. M., Furlanello, C., Biasioli, F., \& Gasperi, F. (2006). Recursive feature elimination with random forest for PTR-MS analysis of agroindustrial products. Chemometrics and Intelligent Laboratory Systems, 83(2), 83-90.

Grassini, P., Cafaro La Menza, N., Rattalino Edreira, J. I., Monzón, J. P., Tenorio, F. A., \& Specht, J. E. (2021). Chapter 8-Soybean. In V. O. Sadras \& D. F. Calderini (Eds.), Crop Physiology Case Histories for Major Crops (pp. 282-319). Academic Press. https://doi.org/10.1016/B978-0-12-

\section{4-1.00008-6}

Guilpart, N., lizumi, T., \& Makowski, D. (2020). Data-driven yield projections suggest large opportunities to improve Europe's soybean self-sufficiency under climate change. BioRxiv, 2020.10.08.331496. https://doi.org/10.1101/2020.10.08.331496

Guyon, I., \& Elisseeff, A. (2003). An introduction to variable and feature selection. Journal of Machine Learning Research, 3(Mar), 1157-1182.

Guyon, I., Weston, J., Barnhill, S., \& Vapnik, V. (2002). Gene Selection for Cancer Classification using Support Vector Machines. Machine Learning, 46(1), 389-422. https://doi.org/10.1023/A:1012487302797

Hornik, K., Buchta, C., \& Zeileis, A. (2009). Open-source machine learning: R meets Weka. Computational Statistics, 24(2), 225-232. https://doi.org/10.1007/s00180-008-0119-7

Jagtap, S. S., \& Jones, J. W. (2002). Adaptation and evaluation of the CROPGRO-soybean model to predict regional yield and production. Agriculture, Ecosystems \& Environment, 93(1), 73-85. https://doi.org/10.1016/\$0167-8809(01)00358-9

Jégo, G., Pattey, E., Bourgeois, G., Morrison, M. J., Drury, C. F., Tremblay, N., \& Tremblay, G. (2010). Calibration and performance evaluation of soybean and spring wheat cultivars using the STICS crop model in Eastern Canada. Field Crops Research, 117(2), 183-196. https://doi.org/10.1016/j.fcr.2010.03.008 
Jing, Q., Huffman, T., Shang, J., Liu, J., Pattey, E., Morrison, M., Jégo, G., \& Qian, B. (2017). Modelling soybean yield responses to seeding date under projected climate change scenarios. Canadian Journal of Plant Science. https://doi.org/10.1139/cjps-2017-0065

Kaul, M., Hill, R. L., \& Walthall, C. (2005). Artificial neural networks for corn and soybean yield prediction. Agricultural Systems, 85(1), 1-18. https://doi.org/10.1016/j.agsy.2004.07.009

Khaki, S., Wang, L., \& Archontoulis, S. V. (2020). A CNN-RNN Framework for Crop Yield Prediction. Frontiers in Plant Science, 10. https://doi.org/10.3389/fpls.2019.01750

Kohavi, R., \& John, G. H. (1997). Wrappers for feature subset selection. Artificial Intelligence, 97(1), 273-324. https://doi.org/10.1016/S0004-3702(97)00043-X

Kothari, K., Salmeron, M., Battisti, R., Boote, K., Archontoulis, S., Confalone, A., Constantin, J., Cuadra Sanatiago, V., Debaeke, P., Faye, B., Grant, B., Hoogen-Boom, G., Jing, Q., Michael Van Der 10, L., Macena, F., Marin, F., Nehbandani, A., Nendel, C., Larry, P., ... Viera Nilson, A. (2020, February). First Soybean Multi-model Sensitivity Analysis to CO 2 , Temperature, Water, and Nitrogen. ICROPM2020: Second International Crop Modelling Symposium, Montpellier. https://hal.inria.fr/hal-02950318

Kross, A., Znoj, E., Callegari, D., Kaur, G., Sunohara, M., Lapen, D. R., \& McNairn, H. (2020). Using Artificial Neural Networks and Remotely Sensed Data to Evaluate the Relative Importance of Variables for Prediction of Within-Field Corn and Soybean Yields. Remote Sensing, 12(14), 2230. https://doi.org/10.3390/rs12142230

Kuhn, M. (2008). Building predictive models in R using the caret package. Journal of Statistical Software, 28(5), 1-26.

Liaw, A., \& Wiener, M. (2002). Classification and regression by randomforest. $R$ News, 2(3), 18-22. Liu, Y., \& Zheng, Y. F. (2006). FS_SFS: A novel feature selection method for support vector machines. Pattern Recognition, 39(7), 1333-1345. 
680

681

682

683

684

685

686

687

688

689

690

691

692

693

694

695

696

697

698

699

700

701

702

703

Loyola-González, O. (2019). Black-Box vs. White-Box: Understanding Their Advantages and Weaknesses From a Practical Point of View. IEEE Access, 7, 154096-154113. https://doi.org/10.1109/ACCESS.2019.2949286

Ma, B. L., Dwyer, L. M., Costa, C., Cober, E. R., \& Morrison, M. J. (2001). Early Prediction of Soybean Yield from Canopy Reflectance Measurements. Agronomy Journal, 93(6), 1227-1234. https://doi.org/10.2134/agronj2001.1227

Maimaitijiang, M., Sagan, V., Sidike, P., Hartling, S., Esposito, F., \& Fritschi, F. B. (2020). Soybean yield prediction from UAV using multimodal data fusion and deep learning. Remote Sensing of Environment, 237, 111599. https://doi.org/10.1016/j.rse.2019.111599

Maldonado, S., \& Weber, R. (2009). A wrapper method for feature selection using Support Vector Machines. Information Sciences, 179(13), 2208-2217. https://doi.org/10.1016/j.ins.2009.02.014

Nehbandani, A., Soltani, A., Nourbakhsh, F., \& Dadrasi, A. (2020). Estimating crop model parameters for simulating soybean production in Iran conditions. $O C L, 27,58$. https://doi.org/10.1051/ocl/2020057

Oil Word. (2020). The OIL WORLD ANNUAL encyclopedia. https://www.oilworld.biz/t/publications/annual

Ovando, G., Sayago, S., \& Bocco, M. (2018). Evaluating accuracy of DSSAT model for soybean yield estimation using satellite weather data. ISPRS Journal of Photogrammetry and Remote Sensing, 138, 208-217. https://doi.org/10.1016/j.isprsjprs.2018.02.015

Pearson, K. (1920). Notes on the History of Correlation. Biometrika, 13(1), 25-45. https://doi.org/10.2307/2331722

Porter, J. R., Xie, L., Challinor, A. J., Cochrane, K., Howden, S. M., Iqbal, M. M., Lobell, D. B., \& Travasso, M. I. (2014). Food security and food production systems. 
Prion, S. K., \& Haerling, K. A. (2020). Making Sense of Methods and Measurements: Simple Linear Regression. Clinical Simulation in Nursing, 48, 94-95. https://doi.org/10.1016/j.ecns.2020.07.004

Purcell, L. C., \& Roekel, R. J. V. (2019). Simulating Soybean Yield Potential under Optimum Management. Agrosystems, Geosciences \& Environment, 2(1), 190029. https://doi.org/10.2134/age2019.04.0029

Quinlan, J. R. (1992). Learning with continuous classes. 5th Australian Joint Conference on Artificial Intelligence, 92, 343-348.

Robertson, M. J., \& Carberry, P. S. (1998). Simulating growth and development of soybean in APSIM. Proceedings, 10th Australian Soybean Conference, 130-136. https://publications.csiro.au/rpr/pub?list=BRO\&pid=procite:e5446cf7-51a2-4606-a66028dadefbf68d

Rudin, C. (2019). Stop explaining black box machine learning models for high stakes decisions and use interpretable models instead. Nature Machine Intelligence, 1(5), 206-215. https://doi.org/10.1038/s42256-019-0048-x

Rumelhart, D. E., Hinton, G. E., \& Williams, R. J. (1986). Learning representations by back-propagating errors. Nature, 323(6088), 533-536.

Schober, P., Boer, C., \& Schwarte, L. A. (2018). Correlation Coefficients: Appropriate Use and Interpretation. Anesthesia and Analgesia, 126(5), 1763-1768. https://doi.org/10.1213/ANE.0000000000002864

Schoving, C. (2020). Analyse écophysiologique et modélisation dynamique des intéractions génotype $x$ environnement $x$ conduite de culture chez le soja [PhD Thesis, Université fédérale Toulouse Midi-Pyrénée]. http://www.theses.fr/s164533

Schwalbert, R. A., Amado, T., Corassa, G., Pott, L. P., Prasad, P. V. V., \& Ciampitti, I. A. (2020). Satellite-based soybean yield forecast: Integrating machine learning and weather data for 
improving crop yield prediction in southern Brazil. Agricultural and Forest Meteorology, 284, 107886. https://doi.org/10.1016/j.agrformet.2019.107886

Shannon, C. E. (1948). A mathematical theory of communication. The Bell System Technical Journal, 27(3), 379-423.

733

734

735

736

737

738

739

740

741

742

743

744

745

746

747

748

749

750

751

752

753

Shi, X., Wang, K., Cheong, T. S., \& Zhang, H. (2020). Prioritizing driving factors of household carbon emissions: An application of the LASSO model with survey data. Energy Economics, 92, 104942. https://doi.org/10.1016/j.eneco.2020.104942

Solorio-Fernández, S., Martínez-Trinidad, J. Fco., \& Carrasco-Ochoa, J. A. (2020). A Supervised Filter Feature Selection method for mixed data based on Spectral Feature Selection and Information-theory redundancy analysis. Pattern Recognition Letters, 138, 321-328. https://doi.org/10.1016/j.patrec.2020.07.039

Spearman, C. (1961). The Proof and Measurement of Association Between Two Things (p. 58). Appleton-Century-Crofts. https://doi.org/10.1037/11491-005

Stepanov, A., Dubrovin, K., Sorokin, A., \& Aseeva, T. (2020). Predicting Soybean Yield at the Regional Scale Using Remote Sensing and Climatic Data. Remote Sensing, 12(12), 1936. https://doi.org/10.3390/rs12121936

Sun, J., Di, L., Sun, Z., Shen, Y., \& Lai, Z. (2019). County-Level Soybean Yield Prediction Using Deep CNN-LSTM Model. Sensors, 19(20), 4363. https://doi.org/10.3390/s19204363

Talavera, L. (2005). An evaluation of filter and wrapper methods for feature selection in categorical clustering. International Symposium on Intelligent Data Analysis, 440-451.

Terres Univia. (2021). Plantes riches en protéines (Chiffres Clés 2020, p. 24). Chiffres Clés 2020. http://www.terresunivia.fr/documentation-presse/chiffres-cles/chiffres-cles

Thirumalai, C., Chandhini, S. A., \& Vaishnavi, M. (2017). Analysing the concrete compressive strength using Pearson and Spearman. 2017 International Conference of Electronics, Communication and Aerospace Technology (ICECA), 2, 215-218. 
Tibshirani, R. (1996). Regression shrinkage and selection via the lasso. Journal of the Royal Statistical Society: Series B (Methodological), 58(1), 267-288.

Vapnik, V. (1995). The nature of statistical learning theory. Springer science \& business media.

Wang, Y., \& Witten, I. H. (1996). Induction of model trees for predicting continuous classes.

Wei, M. C. F., \& Molin, J. P. (2020). Soybean Yield Estimation and Its Components: A Linear Regression Approach. Agriculture, 10(8), 348.

Wolsey, L. A., \& Nemhauser, G. L. (1999). Integer and combinatorial optimization (Vol. 55). John Wiley \& Sons.

Xu, C., \& Katchova, A. L. (2019). Predicting Soybean Yield with NDVI Using a Flexible Fourier Transform Model. Journal of Agricultural and Applied Economics, 51(3), 402-416. https://doi.org/10.1017/aae.2019.5

Yang, P., Zhou, B. B., Zhang, Z., \& Zomaya, A. Y. (2010). A multi-filter enhanced genetic ensemble system for gene selection and sample classification of microarray data. BMC Bioinformatics, 11(1), S5. https://doi.org/10.1186/1471-2105-11-S1-S5

Yu, H., Yang, J., \& Han, J. (2003). Classifying large data sets using SVMs with hierarchical clusters. Proceedings of the Ninth ACM SIGKDD International Conference on Knowledge Discovery and Data Mining, 306-315. 


\section{APPENDIX A}

\begin{tabular}{|c|c|c|c|c|c|c|c|}
\hline $\begin{array}{l}\text { Experimental } \\
\text { site }\end{array}$ & Year & $\begin{array}{l}\text { Maturity } \\
\text { group }\end{array}$ & Variety & Planting date & $\begin{array}{c}\text { Water } \\
\text { management }\end{array}$ & Soil & Observed variables \\
\hline \multirow[t]{2}{*}{ Auzeville } & 2017 & $000, \mathrm{I}, \mathrm{II}$ & $\begin{array}{l}\text { Blancas, Ecudor, Santana, Isidor, } \\
\text { Sultana, RGT, Shouna }\end{array}$ & 80,130 & IRR, DRY & Clay, Loam & LAI, BNF, AGPN, AGB, GY, GNC, Oil \\
\hline & 2018 & $000, \mathrm{I}, \mathrm{II}$ & $\begin{array}{l}\text { Blancas, Ecudor, Santana, Isidor, ES, } \\
\text { Pallador, Sultana, RGT, Shouna }\end{array}$ & 114,155 & IRR, DRY & $\begin{array}{l}\text { Silty, } \quad \text { Clay, } \\
\text { Loam }\end{array}$ & $\begin{array}{l}\text { BNF, AGPN, AGB, GY, GNC, Oil, roots } \\
\text { depth }\end{array}$ \\
\hline \multirow[t]{3}{*}{ Béziers } & 2010 & I, II & $\begin{array}{l}\text { Isidor, Sumatra, Ecudor, Fukui, } \\
\text { S109554 }\end{array}$ & $55,76,112$ & IRR & Loam & GY \\
\hline & 2011 & 0, I, II & Sarema, Isidor, Ecudor & $67,96,132$ & IRR & Loam & GY \\
\hline & 2012 & $0, \mathrm{I}, \mathrm{II}$ & Sarema, Isidor, Ecudor & $76,103,131$ & IRR & Silt, Loam & GY, GNC \\
\hline \multirow[t]{2}{*}{ En Crambade } & 2013 & I, II & Isidor, Santana, Ecudor & 74,115 & IRR, DRY & Clay & LAI, BNF, AGPN, AGB, GY, GNC, Oil \\
\hline & 2014 & I, II & Isidor, Santana, Ecudor & 73,120 & IRR, DRY & Clay & LAI, BNF, AGPN, AGB, GY, GNC, Oil \\
\hline Mauguio & 2010 & I, II & $\begin{array}{l}\text { Isidor, Sumatra, Ecudor, Fukui, } \\
\text { S109554 }\end{array}$ & $74,98,145$ & IRR & Clay, Loam & GY \\
\hline \multirow[t]{5}{*}{ Mondonville } & 2010 & I, II & $\begin{array}{l}\text { Isidor, Sumatra, Ecudor, Fukui, } \\
\text { S109554 }\end{array}$ & $61,92,138$ & IRR & Silt, Loam & GY \\
\hline & 2011 & $0, \mathrm{I}, \mathrm{II}$ & Sarema, Isidor, Ecudor & $80,102,124$ & IRR & Silt, Loam & GY \\
\hline & 2012 & I, II & Isidor, Ecudor & $76,97,124$ & IRR & Silt, Loam & GY, GNC \\
\hline & 2013 & I, II & Isidor, Santana, Ecudor & 81,147 & IRR, DRY & Silt, Loam & LAI, BNF, AGPN, AGB, GY, GNC, Oil \\
\hline & 2014 & I, II & Isidor, Santana, Ecudor & 126 & IRR, DRY & Silt, Loam & LAI, BNF, AGPN, AGB, GY, GNC, Oil \\
\hline \multirow[t]{5}{*}{ Rivières } & 2010 & I, II & $\begin{array}{l}\text { Isidor, Sumatra, Ecudor, Fukui, } \\
\text { S109554 }\end{array}$ & 62,99 & IRR & Clay, Loam & GY \\
\hline & 2011 & 0, I, II & Sarema, Isidor, Ecudor & $70,102,131$ & IRR & Clay, Loam & GY \\
\hline & 2012 & I, II & Isidor, Ecudor & $76,108,138$ & IRR & Clay, Loam & GY, GNC \\
\hline & 2013 & I, II & Isidor, Santana, Ecudor & 81,126 & IRR, DRY & Clay, Loam & LAI, BNF, AGPN, AGB, GY, GNC, Oil \\
\hline & 2014 & I, II & Isidor, Santana, Ecudor & 77,126 & IRR, DRY & Clay, Loam & LAI, BNF, AGPN, AGB, GY, GNC, Oil \\
\hline
\end{tabular}

Table A1. Dataset description of seventeen experimental sites during 2010-2018 from six regions in the south of France. The dataset contains 227 simulation units (USM) created from combination of experimental sites, years and cropping practices (cultivar, water management and sowing date). LAI: Leaf area index (m2.m-2), BNF: fixed nitrogen (kg.ha-1), AGPN: Total nitrogen (kg.ha-

1), AGB: Biomass of aerial parts (t.ha-1), GY: Grain yield (t.ha-1), GNC: Nitrogen concentration in the grains (\%), Oil: percentage of oil (\%), roots depth: rooting depth (cm). Source: (Schoving,

2020) 
Table A2 lists all of the preprocessed variables from STICS basic variables, crop phenology stages, descriptive values and thresholds.

\begin{tabular}{|c|c|c|c|c|c|}
\hline$\#$ & Variable & $\#$ & Variable & $\#$ & Variable \\
\hline 1 & Nbgrmax & 30 & Etpp(n)_cum_Idrp-Imat & 59 & MaxTemp_max_Iflo-Idrp \\
\hline 2 & Stlevdrp & 31 & Etpp(n)_cum_Iflo-Idrp & 60 & $\begin{array}{c}\text { Days_MaxTemp_28_Ilev- } \\
\text { Imat }\end{array}$ \\
\hline 3 & Stflodrp & 32 & Precip_cum_Ilev-Imat & 61 & Days_MaxTemp_28_Iflo-Imat \\
\hline 4 & Stdrpmat & 33 & Precip_cum_Iflo-Imat & 62 & $\begin{array}{c}\text { Days_MaxTemp_28_Idrp- } \\
\text { Imat }\end{array}$ \\
\hline 5 & Masec(n)_Iflo & 34 & Precip_cum_Idrp-Imat & 63 & Days_MaxTemp_28_Iflo-Idrp \\
\hline 6 & Masec(n)_Idrp & 35 & Precip_cum_Iflo-Idrp & 64 & Swfac_avg_Ilev-Imat \\
\hline 7 & Masec(n)_Imat & 36 & Ep_cum_Ilev-Imat & 65 & Swfac_avg_Iflo-Imat \\
\hline 8 & Lai(n)_Iflo & 37 & Ep_cum_Iflo-Imat & 66 & Swfac_avg_Idrp-Imat \\
\hline 9 & Lai(n)_Idrp & 38 & Ep_cum_Idrp-Imat & 67 & Swfac_avg_Iflo-Idrp \\
\hline 10 & Lai(n)_Imat & 39 & Ep_cum_Iflo-Idrp & 68 & Swfac_min_Ilev-Imat \\
\hline 11 & Qnplante_Iflo & 40 & AvgTemp_avg_Ilev-Imat & 69 & Swfac_min_Iflo-Imat \\
\hline 12 & Qnplante_Idrp & 41 & AvgTemp_avg_Iflo-Imat & 70 & Swfac_min_Idrp-Imat \\
\hline 13 & Qnplante_Imat & 42 & AvgTemp_avg_Idrp-Imat & 71 & Swfac_min_Iflo-Idrp \\
\hline 14 & Qfix_Iflo & 43 & AvgTemp_avg_Iflo-Idrp & 72 & Days_Swfac_0.6_Ilev-Imat \\
\hline 15 & Qfix_Idrp & 44 & MinTemp_avg_Ilev-Imat & 73 & Days_Swfac_0.6_Iflo-Imat \\
\hline 16 & Qfix_Imat & 45 & MinTemp_avg_Iflo-Imat & 74 & Days_Swfac_0.6_Idrp-Imat \\
\hline 17 & Zrac_Iflo & 46 & MinTemp_avg_Idrp-Imat & 75 & Days_Swfac_0.6_Iflo-Idrp \\
\hline 18 & Zrac_Idrp & 47 & MinTemp_avg_Iflo-Idrp & 76 & Inn_avg_Ilev-Imat \\
\hline 19 & Zrac_Imat & 48 & Days_MinTemp_18_Ilev-Imat & 77 & Inn_avg_Iflo-Imat \\
\hline 20 & Jul_cum_Ilev-Imat & 49 & Days_MinTemp_18_Iflo-Imat & 78 & Inn_avg_Idrp-Imat \\
\hline 21 & Jul_cum_Iflo-Imat & 50 & $\begin{array}{c}\text { Days_MinTemp_18_Idrp- } \\
\text { Imat }\end{array}$ & 79 & Inn_avg_Iflo-Idrp \\
\hline 22 & Jul_cum_Idrp-Imat & 51 & Days_MinTemp_18_Iflo-Idrp & 80 & Inn_min_Ilev-Imat \\
\hline 23 & Jul_cum_Iflo-Idrp & 52 & MaxTemp_avg_Ilev-Imat & 81 & Inn_min_Iflo-Imat \\
\hline 24 & Raint_cum_Ilev-Imat & 53 & MaxTemp_avg_Iflo-Imat & 82 & Inn_min_Idrp-Imat \\
\hline 25 & Raint_cum_Iflo-Imat & 54 & MaxTemp_avg_Idrp-Imat & 83 & Inn_min_Iflo-Idrp \\
\hline 26 & Raint_cum_Idrp-Imat & 55 & MaxTemp_avg_Iflo-Idrp & 84 & Days_Inn_0.6_Ilev-Imat \\
\hline 27 & Raint_cum_Iflo-Idrp & 56 & MaxTemp_max_Ilev-Imat & 85 & Days_Inn_0.6_Iflo-Imat \\
\hline 28 & Etpp(n)_cum_Ilev-Imat & 57 & MaxTemp_max_Iflo-Imat & 86 & Days_Inn_0.6_Idrp-Imat \\
\hline 29 & Etpp(n)_cum_Iflo-Imat & 58 & MaxTemp_max_Idrp-Imat & 87 & Days_Inn_0.6_Iflo-Idrp \\
\hline
\end{tabular}

Table A2. Name of variables processed from Multidisciplinary Simulator for Standard Crops (STICS). Crop phenology stages: Ilev (emergence), Idrp (grain filling onset), Iflo (flowering), Imat (physiological maturity); descriptive values: cum (cumulative), max (maximum), avg (average); thresholds (MinTemp, MaxTemp, Swfac, Inn variables) 
APPENDIX B

\begin{tabular}{|c|c|c|c|c|c|}
\hline Pos & Variable name & $\begin{array}{c}\text { Var } \\
\text { Importance }\end{array}$ & Pos & Variable name & $\begin{array}{c}\text { Var } \\
\text { Importance }\end{array}$ \\
\hline 1 & Masec(n)_Imat & 0.7923 & 45 & Inn_avg_Iflo-Idrp & 0.3542 \\
\hline 2 & Lai(n)_Imat & 0.7726 & 46 & MinTemp_avg_Ilev-Imat & 0.3508 \\
\hline 3 & Qnplante_Idrp & 0.7710 & 47 & Days_MaxTemp_28_Iflo-Imat & 0.3478 \\
\hline 4 & Qnplante_Imat & 0.7523 & 48 & Precip_cum_Iflo-Idrp & 0.3460 \\
\hline 5 & Masec(n)_Idrp & 0.7334 & 49 & MaxTemp_avg_Iflo-Imat & 0.3432 \\
\hline 6 & Ep_cum_Idrp-Imat & 0.6819 & 50 & Days_MinTemp_18_Iflo-Idrp & 0.3327 \\
\hline 7 & Qfix_Imat & 0.6805 & 51 & Inn_avg_Iflo-Imat & 0.3099 \\
\hline 8 & Ep_cum_Iflo-Imat & 0.6650 & 52 & MinTemp_avg_Iflo-Idrp & 0.2944 \\
\hline 9 & Raint_cum_Idrp-Imat & 0.6326 & 53 & Inn_avg_Ilev-Imat & 0.2924 \\
\hline 10 & Lai(n)_Idrp & 0.6292 & 54 & Days_Inn_0.6_Iflo-Imat & 0.2923 \\
\hline 11 & AvgTemp_avg_Idrp-Imat & 0.6157 & 55 & Days_Inn_0.6_Iflo-Idrp & 0.2923 \\
\hline 12 & Swfac_avg_Iflo-Imat & 0.6088 & 56 & Days_Inn_0.6_Ilev-Imat & 0.2903 \\
\hline 13 & MinTemp_avg_Idrp-Imat & 0.5937 & 57 & Inn_min_Iflo-Imat & 0.2824 \\
\hline 14 & Ep_cum_Ilev-Imat & 0.5842 & 58 & Inn_min_Iflo-Idrp & 0.2684 \\
\hline 15 & Days_Swfac_0.6_Iflo-Imat & 0.5811 & 59 & Inn_min_Idrp-Imat & 0.2673 \\
\hline 16 & MinTemp_avg_Iflo-Imat & 0.5654 & 60 & Precip_cum_Idrp-Imat & 0.2453 \\
\hline 17 & Swfac_min_Idrp-Imat & 0.5638 & 61 & Inn_min_Ilev-Imat & 0.2405 \\
\hline 18 & Days_MinTemp_18_Idrp-Imat & 0.5618 & 62 & AvgTemp_avg_Ilev-Imat & 0.2320 \\
\hline 19 & Swfac_min_Iflo-Imat & 0.5600 & 63 & Jul_cum_Ilev-Imat & 0.1721 \\
\hline 20 & MaxTemp_avg_Idrp-Imat & 0.5578 & 64 & Masec(n)_Iflo & 0.1698 \\
\hline 21 & AvgTemp_avg_Iflo-Imat & 0.5551 & 65 & Lai(n)_Iflo & 0.1594 \\
\hline 22 & Swfac_min_Ilev-Imat & 0.5521 & 66 & MaxTemp_max_Ilev-Imat & 0.1560 \\
\hline 23 & Days_MinTemp_18_Iflo-Imat & 0.5328 & 67 & Inn_avg_Idrp-Imat & 0.1557 \\
\hline 24 & $\begin{array}{l}\text { Days_MaxTemp_28_Idrp- } \\
\text { Imat }\end{array}$ & 0.5119 & 68 & Days_MaxTemp_28_Ilev-Imat & 0.1442 \\
\hline 25 & Ep_cum_Iflo-Idrp & 0.5113 & 69 & AvgTemp_avg_Iflo-Idrp & 0.1030 \\
\hline 26 & Jul_cum_Idrp-Imat & 0.5069 & 70 & Zrac_Iflo & 0.0934 \\
\hline 27 & Swfac_avg_Ilev-Imat & 0.5054 & 71 & Etpp(n)_cum_Idrp-Imat & 0.0858 \\
\hline 28 & Qfix_Idrp & 0.4953 & 72 & MaxTemp_avg_Iflo-Idrp & 0.0856 \\
\hline 29 & Swfac_avg_Idrp-Imat & 0.4929 & 73 & Qfix_Iflo & 0.0821 \\
\hline 30 & Swfac_avg_Iflo-Idrp & 0.4909 & 74 & Nbgrmax & 0.0781 \\
\hline 31 & Days_Swfac_0.6_Ilev-Imat & 0.4899 & 75 & MaxTemp_max_Iflo-Imat & 0.0773 \\
\hline 32 & Days_Swfac_0.6_Iflo-Idrp & 0.4834 & 76 & Etpp(n)_cum_Ilev-Imat & 0.0708 \\
\hline 33 & Raint_cum_Iflo-Imat & 0.4712 & 77 & Etpp(n)_cum_Iflo-Imat & 0.0701 \\
\hline 34 & Days_Swfac_0.6_Idrp-Imat & 0.4627 & 78 & Days_MaxTemp_28_Iflo-Idrp & 0.0643 \\
\hline 35 & Zrac_Idrp & 0.4592 & 79 & MaxTemp_max_Iflo-Idrp & 0.0618 \\
\hline 36 & Zrac_Imat & 0.4536 & 80 & MaxTemp_avg_Ilev-Imat & 0.0613 \\
\hline 37 & Swfac_min_Iflo-Idrp & 0.4464 & 81 & Etpp(n)_cum_Iflo-Idrp & 0.0565 \\
\hline 38 & MaxTemp_max_Idrp-Imat & 0.4257 & 82 & Raint_cum_Iflo-Idrp & 0.0461 \\
\hline 39 & Jul_cum_Iflo-Imat & 0.3997 & 83 & Jul_cum_Iflo-Idrp & 0.0456 \\
\hline 40 & Days_MinTemp_18_Ilev-Imat & 0.3926 & 84 & Stflodrp & 0.0372 \\
\hline 41 & Qnplante_Iflo & 0.3866 & 85 & Stlevdrp & 0.0308 \\
\hline 42 & Raint_cum_Ilev-Imat & 0.3802 & 86 & Stdrpmat & 0.0074 \\
\hline 43 & Precip_cum_Ilev-Imat & 0.3714 & 87 & Days_Inn_0.6_Idrp-Imat & 0.0000 \\
\hline 44 & Precip_cum_Iflo-Imat & 0.3585 & & & \\
\hline
\end{tabular}

Table B1. Ranking of variables computed by Pearson correlation. 


\begin{tabular}{|c|c|c|c|c|c|}
\hline Pos & Variable name & $\begin{array}{c}\text { Var } \\
\text { Importance }\end{array}$ & Pos & Variable name & $\begin{array}{c}\text { Var } \\
\text { Importance }\end{array}$ \\
\hline 1 & Lai(n)_Imat & 0.7699 & 45 & Precip_cum_Iflo-Imat & 0.3140 \\
\hline 2 & Masec(n)_Imat & 0.7311 & 46 & Days_MinTemp_18_Iflo-Idrp & 0.3018 \\
\hline 3 & Qnplante_Idrp & 0.7137 & 47 & Inn_avg_Iflo-Idrp & 0.2983 \\
\hline 4 & $\operatorname{Masec}(\mathrm{n}) \_$Idrp & 0.7003 & 48 & MinTemp_avg_Ilev-Imat & 0.2851 \\
\hline 5 & Ep_cum_Iflo-Imat & 0.6886 & 49 & Inn_min_Idrp-Imat & 0.2817 \\
\hline 6 & Ep_cum_Idrp-Imat & 0.6734 & 50 & Precip_cum_Ilev-Imat & 0.2602 \\
\hline 7 & Qnplante_Imat & 0.6714 & 51 & Days_Inn_0.6_Ilev-Imat & 0.2599 \\
\hline 8 & Ep_cum_Ilev-Imat & 0.6456 & 52 & Days_Inn_0.6_Iflo-Imat & 0.2599 \\
\hline 9 & Lai(n)_Idrp & 0.6439 & 53 & Days_Inn_0.6_Iflo-Idrp & 0.2599 \\
\hline 10 & Raint_cum_Idrp-Imat & 0.6288 & 54 & Inn_avg_Iflo-Imat & 0.2570 \\
\hline 11 & Swfac_min_Idrp-Imat & 0.6160 & 55 & Precip_cum_Iflo-Idrp & 0.2407 \\
\hline 12 & Swfac_min_Iflo-Imat & 0.6136 & 56 & Inn_min_Iflo-Idrp & 0.2370 \\
\hline 13 & AvgTemp_avg_Idrp-Imat & 0.6081 & 57 & Inn_avg_Ilev-Imat & 0.2353 \\
\hline 14 & Swfac_min_Ilev-Imat & 0.6009 & 58 & MinTemp_avg_Iflo-Idrp & 0.2174 \\
\hline 15 & MinTemp_avg_Idrp-Imat & 0.5977 & 59 & Masec(n)_Iflo & 0.2164 \\
\hline 16 & Qfix_Imat & 0.5964 & 60 & Inn_min_Iflo-Imat & 0.2155 \\
\hline 17 & MaxTemp_avg_Idrp-Imat & 0.5937 & 61 & Lai(n)_Iflo & 0.2105 \\
\hline 18 & Days_MinTemp_18_Idrp-Imat & 0.5876 & 62 & Inn_min_Ilev-Imat & 0.1991 \\
\hline 19 & MinTemp_avg_Iflo-Imat & 0.5758 & 63 & Jul_cum_Ilev-Imat & 0.1979 \\
\hline 20 & Swfac_avg_Iflo-Imat & 0.5655 & 64 & $\begin{array}{l}\text { Days_MaxTemp_28_Ilev- } \\
\text { Imat }\end{array}$ & 0.1840 \\
\hline 21 & AvgTemp_avg_Iflo-Imat & 0.5548 & 65 & AvgTemp_avg_Ilev-Imat & 0.1831 \\
\hline 22 & Days_MinTemp_18_Iflo-Imat & 0.5510 & 66 & MaxTemp_max_Ilev-Imat & 0.1801 \\
\hline 23 & Ep_cum_Iflo-Idrp & 0.5482 & 67 & Inn_avg_Idrp-Imat & 0.1667 \\
\hline 24 & Jul_cum_Idrp-Imat & 0.5380 & 68 & Precip_cum_Idrp-Imat & 0.1519 \\
\hline 25 & Days_Swfac_0.6_Iflo-Imat & 0.5361 & 69 & AvgTemp_avg_Iflo-Idrp & 0.1400 \\
\hline 26 & $\begin{array}{l}\text { Days_MaxTemp_28_Idrp- } \\
\text { Imat }\end{array}$ & 0.5033 & 70 & Qfix_Iflo & 0.1263 \\
\hline 27 & Qfix_Idrp & 0.4679 & 71 & Nbgrmax & 0.1160 \\
\hline 28 & Jul_cum_Iflo-Imat & 0.4667 & 72 & Etpp(n)_cum_Idrp-Imat & 0.1095 \\
\hline 29 & MaxTemp_max_Idrp-Imat & 0.4629 & 73 & Raint_cum_Iflo-Idrp & 0.1015 \\
\hline 30 & Raint_cum_Iflo-Imat & 0.4590 & 74 & MaxTemp_max_Iflo-Imat & 0.0949 \\
\hline 31 & Days_Swfac_0.6_Ilev-Imat & 0.4546 & 75 & Jul_cum_Iflo-Idrp & 0.0849 \\
\hline 32 & Swfac_avg_Ilev-Imat & 0.4364 & 76 & MaxTemp_avg_Ilev-Imat & 0.0763 \\
\hline 33 & Swfac_avg_Idrp-Imat & 0.4319 & 77 & Etpp(n)_cum_Ilev-Imat & 0.0763 \\
\hline 34 & Raint_cum_Ilev-Imat & 0.4209 & 78 & Etpp(n)_cum_Iflo-Idrp & 0.0736 \\
\hline 35 & Qnplante_Iflo & 0.4206 & 79 & Etpp(n)_cum_Iflo-Imat & 0.0731 \\
\hline 36 & Days_Swfac_0.6_Idrp-Imat & 0.4148 & 80 & Zrac_Iflo & 0.0720 \\
\hline 37 & Swfac_avg_Iflo-Idrp & 0.4131 & 81 & Days_MaxTemp_28_Iflo-Idrp & 0.0538 \\
\hline 38 & Swfac_min_Iflo-Idrp & 0.4105 & 82 & Stflodrp & 0.0465 \\
\hline 39 & Days_Swfac_0.6_Iflo-Idrp & 0.3993 & 83 & MaxTemp_avg_Iflo-Idrp & 0.0345 \\
\hline 40 & Days_MinTemp_18_Ilev-Imat & 0.3857 & 84 & MaxTemp_max_Iflo-Idrp & 0.0235 \\
\hline 41 & Days_MaxTemp_28_Iflo-Imat & 0.3552 & 85 & Stlevdrp & 0.0085 \\
\hline 42 & Zrac_Idrp & 0.3287 & 86 & Stdrpmat & 0.0085 \\
\hline 43 & MaxTemp_avg_Iflo-Imat & 0.3273 & 87 & Days_Inn_0.6_Idrp-Imat & 0.0000 \\
\hline 44 & Zrac_Imat & 0.3214 & & & \\
\hline
\end{tabular}

Table B2. Ranking of variables computed by Spearman correlation filter. 


\begin{tabular}{|c|c|c|c|c|c|}
\hline Pos & Variable name & $\begin{array}{c}\text { Var } \\
\text { Importance }\end{array}$ & Pos & Variable name & $\begin{array}{c}\text { Var } \\
\text { Importance }\end{array}$ \\
\hline 1 & Lai(n)_Imat & 0.5929 & 45 & Inn_min_Iflo-Imat & 0.1745 \\
\hline 2 & Masec(n)_Imat & 0.5875 & 46 & Inn_avg_Idrp-Imat & 0.1744 \\
\hline 3 & Qnplante_Imat & 0.5515 & 47 & MinTemp_avg_Iflo-Imat & 0.1687 \\
\hline 4 & Ep_cum_Idrp-Imat & 0.4223 & 48 & Inn_min_Idrp-Imat & 0.1673 \\
\hline 5 & Qfix_Imat & 0.4072 & 49 & Days_Swfac_0.6_Ilev-Imat & 0.1628 \\
\hline 6 & Inn_min_Iflo-Idrp & 0.3799 & 50 & $\begin{array}{l}\text { Days_MaxTemp_28_Ilev- } \\
\text { Imat }\end{array}$ & 0.1595 \\
\hline 7 & Inn_avg_Iflo-Idrp & 0.3652 & 51 & Lai(n)_Iflo & 0.1540 \\
\hline 8 & Ep_cum_Iflo-Imat & 0.3486 & 52 & Precip_cum_Ilev-Imat & 0.1213 \\
\hline 9 & Days_Swfac_0.6_Iflo-Imat & 0.3443 & 53 & AvgTemp_avg_Ilev-Imat & 0.1204 \\
\hline 10 & Inn_avg_Ilev-Imat & 0.3400 & 54 & MaxTemp_avg_Ilev-Imat & 0.1204 \\
\hline 11 & Inn_avg_Iflo-Imat & 0.3380 & 55 & Etpp(n)_cum_Iflo-Imat & 0.0993 \\
\hline 12 & Masec(n)_Idrp & 0.3300 & 56 & Etpp(n)_cum_Ilev-Imat & 0.0993 \\
\hline 13 & Qnplante_Idrp & 0.3285 & 57 & Etpp(n)_cum_Iflo-Idrp & 0.0993 \\
\hline 14 & Raint_cum_Idrp-Imat & 0.3080 & 58 & Masec(n)_Iflo & 0.0000 \\
\hline 15 & Days_Swfac_0.6_Iflo-Idrp & 0.3025 & 59 & Qfix_Iflo & 0.0000 \\
\hline 16 & Precip_cum_Iflo-Imat & 0.2988 & 60 & Zrac_Iflo & 0.0000 \\
\hline 17 & Qnplante_Iflo & 0.2895 & 61 & Etpp(n)_cum_Idrp-Imat & 0.0000 \\
\hline 18 & Ep_cum_Ilev-Imat & 0.2833 & 62 & Precip_cum_Idrp-Imat & 0.0000 \\
\hline 19 & Swfac_avg_Iflo-Imat & 0.2758 & 63 & MaxTemp_avg_Iflo-Imat & 0.0000 \\
\hline 20 & Lai(n)_Idrp & 0.2711 & 64 & MaxTemp_max_Iflo-Imat & 0.0000 \\
\hline 21 & Swfac_min_Iflo-Imat & 0.2476 & 65 & Raint_cum_Ilev-Imat & 0.0000 \\
\hline 22 & Swfac_min_Ilev-Imat & 0.2476 & 66 & MinTemp_avg_Ilev-Imat & 0.0000 \\
\hline 23 & Zrac_Idrp & 0.2457 & 67 & Swfac_avg_Ilev-Imat & 0.0000 \\
\hline 24 & Zrac_Imat & 0.2457 & 68 & MaxTemp_max_Ilev-Imat & 0.0000 \\
\hline 25 & MinTemp_avg_Idrp-Imat & 0.2374 & 69 & Inn_min_Ilev-Imat & 0.0000 \\
\hline 26 & Swfac_min_Iflo-Idrp & 0.2309 & 70 & Jul_cum_Ilev-Imat & 0.0000 \\
\hline 27 & Swfac_min_Idrp-Imat & 0.2289 & 71 & Raint_cum_Iflo-Idrp & 0.0000 \\
\hline 28 & AvgTemp_avg_Iflo-Imat & 0.2266 & 72 & AvgTemp_avg_Iflo-Idrp & 0.0000 \\
\hline 29 & MaxTemp_avg_Idrp-Imat & 0.2222 & 73 & MinTemp_avg_Iflo-Idrp & 0.0000 \\
\hline 30 & Days_MinTemp_18_Ilev-Imat & 0.2214 & 74 & MaxTemp_avg_Iflo-Idrp & 0.0000 \\
\hline 31 & Jul_cum_Iflo-Imat & 0.2191 & 75 & MaxTemp_max_Iflo-Idrp & 0.0000 \\
\hline 32 & Days_MinTemp_18_Iflo-Imat & 0.2063 & 76 & Jul_cum_Iflo-Idrp & 0.0000 \\
\hline 33 & AvgTemp_avg_Idrp-Imat & 0.2049 & 77 & Days_Inn_0.6_Ilev-Imat & 0.0000 \\
\hline 34 & Days_MinTemp_18_Idrp-Imat & 0.2035 & 78 & $\begin{array}{l}\text { Days_MaxTemp_28_Iflo- } \\
\text { Imat }\end{array}$ & 0.0000 \\
\hline 35 & MaxTemp_max_Idrp-Imat & 0.2000 & 79 & Days_Inn_0.6_Iflo-Imat & 0.0000 \\
\hline 36 & Qfix_Idrp & 0.1980 & 80 & Days_Inn_0.6_Idrp-Imat & 0.0000 \\
\hline 37 & Ep_cum_Iflo-Idrp & 0.1971 & 81 & Days_MinTemp_18_Iflo-Idrp & 0.0000 \\
\hline 38 & Jul_cum_Idrp-Imat & 0.1969 & 82 & Days_MaxTemp_28_Iflo-Idrp & 0.0000 \\
\hline 39 & Days_MaxTemp_28_Idrp-Imat & 0.1954 & 83 & Days_Inn_0.6_Iflo-Idrp & 0.0000 \\
\hline 40 & Raint_cum_Iflo-Imat & 0.1927 & 84 & Nbgrmax & 0.0000 \\
\hline 41 & Swfac_avg_Idrp-Imat & 0.1883 & 85 & Stlevdrp & 0.0000 \\
\hline 42 & Days_Swfac_0.6_Idrp-Imat & 0.1883 & 86 & Stflodrp & 0.0000 \\
\hline 43 & Precip_cum_Iflo-Idrp & 0.1872 & 87 & Stdrpmat & 0.0000 \\
\hline 44 & Swfac_avg_Iflo-Idrp & 0.1829 & & & \\
\hline
\end{tabular}

Table B3. Ranking of variables computed by filter of entropy-based information gain. 


\section{Coefficients of linear regression created by LASSO}

\begin{tabular}{|c|c|c|c|c|c|}
\hline \# & Variable name & $\begin{array}{c}\text { Coefficient } \\
\text { value }\end{array}$ & \# & Variable name & $\begin{array}{c}\text { Coefficient } \\
\text { value }\end{array}$ \\
\hline 1 & Masec(n)_Iflo & $2.8188 \mathrm{e}+00$ & 34 & Inn_min_Iflo-Imat & $-1.3651 \mathrm{e}+01$ \\
\hline 2 & Lai(n)_Iflo & $9.3241 \mathrm{e}-01$ & 35 & Raint_cum_Ilev-Imat & $-1.1394 \mathrm{e}-02$ \\
\hline 3 & Qnplante_Iflo & $7.4166 \mathrm{e}-02$ & 36 & Precip_cum_Ilev-Imat & $5.6827 \mathrm{e}-03$ \\
\hline 4 & Qfix_Iflo & $-1.7155 \mathrm{e}-01$ & 37 & Ep_cum_Ilev-Imat & $-7.9358 \mathrm{e}-02$ \\
\hline 5 & Zrac_Iflo & $7.6535 \mathrm{e}-02$ & 38 & MinTemp_avg_Ilev-Imat & $1.2562 \mathrm{e}-01$ \\
\hline 6 & Masec(n)_Idrp & $-4.0427 e-01$ & 39 & MaxTemp_avg_Ilev-Imat & $-3.7455 \mathrm{e}-04$ \\
\hline 7 & Lai(n)_Idrp & $7.3189 \mathrm{e}-01$ & 40 & Swfac_avg_Ilev-Imat & $6.1859 \mathrm{e}+00$ \\
\hline 8 & Qnplante_Idrp & $-9.3804 \mathrm{e}-02$ & 41 & Inn_avg_Ilev-Imat & $1.6985 \mathrm{e}+01$ \\
\hline 9 & Qfix_Idrp & $9.1514 \mathrm{e}-02$ & 42 & MaxTemp_max_Ilev-Imat & $7.1837 \mathrm{e}-01$ \\
\hline 10 & Zrac_Idrp & $5.0038 \mathrm{e}-02$ & 43 & Swfac_min_Ilev-Imat & $1.4684 \mathrm{e}-01$ \\
\hline 11 & Masec(n)_Imat & $5.1417 \mathrm{e}-01$ & 44 & Inn_min_Ilev-Imat & $-3.9823 \mathrm{e}+00$ \\
\hline 12 & Lai(n)_Imat & $-4.0912 \mathrm{e}-01$ & 45 & Jul_cum_Ilev-Imat & $-7.5989 \mathrm{e}-02$ \\
\hline 13 & Qnplante_Imat & $3.8100 \mathrm{e}-02$ & 46 & Precip_cum_Iflo-Idrp & $6.9931 \mathrm{e}-03$ \\
\hline 14 & Qfix_Imat & $-5.2369 \mathrm{e}-02$ & 47 & Ep_cum_Iflo-Idrp & $2.4697 \mathrm{e}-02$ \\
\hline 15 & Zrac_Imat & $-6.7964 \mathrm{e}-02$ & 48 & MinTemp_avg_Iflo-Idrp & $3.9772 \mathrm{e}+00$ \\
\hline 16 & Raint_cum_Idrp-Imat & $9.6513 \mathrm{e}-03$ & 49 & MaxTemp_avg_Iflo-Idrp & $-2.6303 e+00$ \\
\hline 17 & Precip_cum_Idrp-Imat & $-2.8790 \mathrm{e}-03$ & 50 & Swfac_avg_Iflo-Idrp & $1.6022 \mathrm{e}+01$ \\
\hline 18 & MinTemp_avg_Idrp-Imat & $4.7465 \mathrm{e}+00$ & 51 & Inn_avg_Iflo-Idrp & $1.1904 \mathrm{e}+01$ \\
\hline 19 & MaxTemp_avg_Idrp-Imat & $-3.7388 \mathrm{e}+00$ & 52 & MaxTemp_max_Iflo-Idrp & $-8.1299 \mathrm{e}-01$ \\
\hline 20 & Swfac_avg_Idrp-Imat & $1.2500 \mathrm{e}+01$ & 53 & Swfac_min_Iflo-Idrp & $-4.1521 \mathrm{e}-01$ \\
\hline 21 & Inn_avg_Idrp-Imat & $3.1469 \mathrm{e}+01$ & 54 & Inn_min_Iflo-Idrp & $2.0532 \mathrm{e}+01$ \\
\hline 22 & MaxTemp_max_Idrp-Imat & $-4.1193 \mathrm{e}-01$ & 55 & Jul_cum_Iflo-Idrp & $4.9970 \mathrm{e}-01$ \\
\hline 23 & Swfac_min_Idrp-Imat & $-1.3343 e+00$ & 56 & Days_MinTemp_18_Ilev-Imat & $1.8624 \mathrm{e}-02$ \\
\hline 24 & Inn_min_Idrp-Imat & $-1.2703 e+00$ & 57 & $\begin{array}{l}\text { Days_MaxTemp_28_Ilev- } \\
\text { Imat }\end{array}$ & $4.6168 \mathrm{e}-02$ \\
\hline 25 & Jul_cum_Idrp-Imat & $-2.3218 \mathrm{e}-01$ & 58 & Days_Swfac_0.6_Ilev-Imat & $3.6354 \mathrm{e}-03$ \\
\hline 26 & Raint_cum_Iflo-Imat & $5.7320 \mathrm{e}-03$ & 59 & Days_MinTemp_18_Iflo-Imat & $-2.3197 \mathrm{e}-02$ \\
\hline 27 & Ep_cum_Iflo-Imat & $7.4176 \mathrm{e}-02$ & 60 & $\begin{array}{l}\text { Days_MaxTemp_28_Iflo- } \\
\text { Imat }\end{array}$ & $-1.7790 \mathrm{e}-01$ \\
\hline 28 & MinTemp_avg_Iflo-Imat & $-9.4243 e+00$ & 61 & Days_Swfac_0.6_Iflo-Imat & $1.0801 \mathrm{e}-02$ \\
\hline 29 & MaxTemp_avg_Iflo-Imat & $7.7822 \mathrm{e}+00$ & 62 & Days_MinTemp_18_Iflo-Idrp & $-1.0127 \mathrm{e}-01$ \\
\hline 30 & Swfac_avg_Iflo-Imat & $-2.8792 \mathrm{e}+01$ & 63 & Days_MaxTemp_28_Iflo-Idrp & $-8.3875 \mathrm{e}-04$ \\
\hline 31 & Inn_avg_Iflo-Imat & $-4.6737 e+01$ & 64 & Days_Swfac_0.6_Iflo-Idrp & $5.2675 \mathrm{e}-03$ \\
\hline 32 & MaxTemp_max_Iflo-Imat & $-1.6202 \mathrm{e}-03$ & 65 & Nbgrmax & $5.1039 \mathrm{e}-04$ \\
\hline 33 & Swfac_min_Iflo-Imat & $6.6187 \mathrm{e}-02$ & 66 & Stdrpmat & $9.8675 \mathrm{e}-03$ \\
\hline
\end{tabular}

Table C1. Coefficients of linear regression created by LASSO. Coefficients equal to zero were assigned to 11 variables.

\section{Linear regressions created by M5 decision tree}

Linear regression number 1:

Mafruit $=-0.2193 *$ Lai $(n) \_I f l o+0.0187 *$ Qnplante_Iflo $-0.0314 *$ Qfix_Iflo $+0.0869 *$ Lai $(n) \_I d r p+0.0759$ $*$ Masec(n)_Imat $+0.002 *$ Qfix_Imat $+3.9514 *$ Inn_avg_Iflo-Idrp - 1.665*Inn_min_Iflo-Idrp - 1.0665

\section{Linear regression number 2:}

Mafruit $=-0.243 *$ Masec(n)_Iflo $-0.2193 *$ Lai(n)_Iflo $+0.0305 *$ Qnplante_Iflo $-0.0179 *$ Qfix_Iflo +0.0047 $*$ Zrac_Iflo $+0.0869 *$ Lai $(n) \_I d r p+0.0434 *$ Masec $(n) \_I m a t+0.002 * Q f i x \_I m a t+0.0036 * E p \_c u m \_I d r p-$ Imat $+0.0287 *$ MaxTemp_avg_Ilev-Imat $+3.2551 *$ Inn_avg_Iflo-Idrp - $1.665 *$ Inn_min_Iflo-Idrp - 1.7154 


\section{Linear regression number 3:}

Mafruit $=-0.4282 *$ Masec(n)_Iflo $-0.2193 *$ Lai(n)_Iflo $+0.0242 *$ Qnplante_Iflo $-0.0398 *$ Qfix_Iflo +0.0869

$*$ Lai $(n) \_I d r p+0.0434 *$ Masec(n)_Imat $+0.002 *$ Qfix_Imat $+0.0032 *$ Ep_cum_Idrp-Imat $+0.0258 *$ MaxTemp_avg_Ilev-Imat $+3.2551 * I n n \_a v g \_I f l o-I d r p-1.665 * I n n \_m i n \_I f l o-I d r p-0.1411$

\section{Linear regression number 4:}

Mafruit $=-0.4282 *$ Masec(n)_Iflo $-0.2193 *$ Lai $(n) \_I f l o+0.0242 *$ Qnplante_Iflo $-0.0398 *$ Qfix_Iflo +0.0869 $*$ Lai $(n) \_I d r p+0.0434 *$ Masec(n)_Imat $+0.002 *$ Qfix_Imat $+0.0032 *$ Ep_cum_Idrp-Imat $+0.0258 *$ MaxTemp_avg_Ilev-Imat $+3.2551 *$ Inn_avg_Iflo-Idrp - $1.665 *$ Inn_min_Iflo-Idrp - 0.1438

\section{Linear regression number 5:}

Mafruit $=-0.4587 * \operatorname{Masec}(n) \_I f l o-0.2193 *$ Lai $(n) \_I f l o+0.0242 *$ Qnplante_Iflo $-0.0401 *$ Qfix_Iflo +0.0869 $*$ Lai $(n) \_I d r p+0.0434 *$ Masec(n)_Imat $+0.002 *$ Qfix_Imat $+0.0032 *$ Ep_cum_Idrp-Imat $+0.0258 *$ MaxTemp_avg_Ilev-Imat $+3.2551 * I n n \_a v g \_I f l o-I d r p-1.665 * I n n \_m i n \_I f l o-I d r p-0.0967$

\section{Linear regression number 6:}

Mafruit $=-0.3026 *$ Masec(n)_Iflo $-0.2193 *$ Lai $(n) \_I f l o+0.0242 *$ Qnplante_Iflo $-0.0312 *$ Qfix_Iflo +0.0869 $*$ Lai $(n) \_I d r p+0.0434 *$ Masec(n)_Imat $+0.002 *$ Qfix_Imat $+0.0032 *$ Ep_cum_Idrp-Imat $+0.0258 *$ MaxTemp_avg_Ilev-Imat $+3.2551 * I n n \_a v g \_I f l o-I d r p-1.665 * I n n \_m i n \_I f l o-I d r p-0.5323$

\section{Linear regression number 7:}

Mafruit $=-0.2811 *$ Masec $(n) \_I f l o+0.0803 *$ Lai $(n) \_I f l o+0.0067 *$ Qnplante_Iflo $+0.0383 *$ Qfix_Iflo +0.0881 $*$ Masec(n)_Idrp $+0.0103 *$ Lai(n)_Idrp $+0.0017 *$ Qfix_Imat $-0.0046 *$ Ep_cum_Idrp-Imat $+0.7974 *$ $S w f a c \_a v g \_I d r p-I m a t+0.577 * S w f a c \_a v g \_I f l o-I m a t+3.8547 * I n n \_a v g \_I f l o-I d r p-2.4314 * I n n \_m i n \_I f l o-I d r p$ $+0.256$

\section{Linear regression number 8:}

Mafruit $=-0.1899 *$ Masec $(n) \_I f l o+0.0274 *$ Lai $(n) \_I f l o+0.0067 *$ Qnplante_Iflo $+0.0223 *$ Qfix_Iflo +0.0881 $*$ Masec(n)_Idrp $+0.0256 *$ Lai $(n) \_I d r p+0.0017 *$ Qfix_Imat $-0.0041 *$ Ep_cum_Idrp-Imat $+0.7974 *$ Swfac_avg_Idrp-Imat $+0.6392 * S w f a c \_a v g \_I f l o-I m a t+3.8547 * I n n \_a v g \_I f l o-I d r p-2.4314 * I n n \_m i n \_I f l o-$ $I d r p+0.1624$

\section{Linear regression number 9:}

Mafruit $=-0.1928 *$ Masec(n)_Iflo $+0.0274 *$ Lai $(n) \_I f l o+0.0067 *$ Qnplante_Iflo $+0.0223 *$ Qfix_Iflo +0.0881 $*$ Masec(n)_Idrp + 0.0256*Lai(n)_Idrp + 0.0017*Qfix_Imat $-0.0041 *$ Ep_cum_Idrp-Imat $+0.7974 *$ $S w f a c \_a v g \_I d r p-I m a t+0.6669 * S w f a c \_a v g \_I f l o-I m a t+3.8547 * I n n \_a v g \_I f l o-I d r p-2.4314 * I n n \_m i n \_I f l o-$ $I d r p+0.1587$

\section{Linear regression number 10:}

Mafruit $=-0.1928 *$ Masec(n)_Iflo $+0.0274 *$ Lai(n)_Iflo $+0.0067 *$ Qnplante_Iflo $+0.0223 *$ Qfix_Iflo +0.0881 $*$ Masec(n)_Idrp $+0.0256 *$ Lai $(n) \_I d r p+0.0017 *$ Qfix_Imat $-0.0041 *$ Ep_cum_Idrp-Imat $+0.7974 *$ $S w f a c \_a v g \_I d r p-I m a t+0.3752 * S w f a c \_a v g \_I f l o-I m a t+3.8547 * I n n \_a v g \_I f l o-I d r p-2.4314 * I n n \_m i n \_I f l o-$ $I d r p+0.3922$

\section{Linear regression number 11:}

Mafruit $=-0.163 *$ Masec(n)_Iflo $-0.2727 *$ Lai $(n) \_I f l o+0.0067 *$ Qnplante_Iflo $+0.0228 *$ Qfix_Iflo +0.0881 $*$ Masec(n)_Idrp + 0.0528*Lai(n)_Idrp + 0.0017*Qfix_Imat $-0.0032 *$ Ep_cum_Idrp-Imat + $1.002 *$ Swfac_avg_Idrp-Imat $+0.1212 * S w f a c \_a v g \_I f l o-I m a t+3.8547 * I n n \_a v g \_I f l o-I d r p-2.0948 * I n n \_m i n \_I f l o-$ $\operatorname{Idrp}+0.6173$ 


\section{Linear regression number 12:}

Mafruit $=-0.163 *$ Masec(n)_Iflo $-0.1797 *$ Lai $(n) \_I f l o+0.0067 *$ Qnplante_Iflo $+0.0234 *$ Qfix_Iflo +0.0881 $*$ Masec(n)_Idrp $+0.0528 *$ Lai $(n) \_I d r p+0.0017 *$ Qfix_Imat $-0.0032 *$ Ep_cum_Idrp-Imat $+1.0215 *$ Swfac_avg_Idrp-Imat $+0.1212 *$ Swfac_avg_Iflo-Imat $+3.8547 *$ Inn_avg_Iflo-Idrp $-2.0948 *$ Inn_min_Iflo$I d r p+0.3868$

\section{Linear regression number 13:}

Mafruit $=-0.0608 *$ Lai $(n) \_I f l o+0.0067 *$ Qnplante_Iflo $+0.0881 *$ Masec $(n) \_I d r p+0.0528 *$ Lai $(n) \_I d r p+$ $0.0017 *$ Qfix_Imat $-0.0032 *$ Ep_cum_Idrp-Imat $+0.7974 * S w f a c \_a v g \_I d r p-I m a t+0.0005 * P r e c i p \_c u m \_I f l o-$ $I m a t+0.1593 * S w f a c \_a v g \_I f l o-I m a t+5.2879 * I n n \_a v g \_I f l o-I d r p-4.1489 * I n n \_m i n \_I f l o-I d r p+0.3625$

\section{Linear regression number 14:}

Mafruit $=-0.0608 *$ Lai $(n) \_I f l o+0.0067 *$ Qnplante_Iflo $+0.102 *$ Masec $(n) \_I d r p+0.0528 *$ Lai $(n) \_I d r p+$ $0.0017 *$ Qfix_Imat $-0.0032 * E p \_c u m \_I d r p-I m a t+0.7974 * S w f a c \_a v g \_I d r p-I m a t+0.0004 *$ Precip_cum_Iflo$I m a t+0.1593 * S w f a c \_a v g \_I f l o-I m a t+5.2879 * I n n \_a v g \_I f l o-I d r p-4.1489 * I n n \_m i n \_I f l o-I d r p+0.3484$

\section{Linear regression number 15:}

Mafruit $=-0.0608 *$ Lai $(n) \_I f l o+0.0067 *$ Qnplante_Iflo $+0.1013 *$ Masec $(n) \_I d r p+0.0528 *$ Lai $(n) \_I d r p+$ $0.0017 *$ Qfix_Imat $-0.0032 *$ Ep_cum_Idrp-Imat $+0.7974 * S w f a c \_a v g \_I d r p-I m a t+0.0004 *$ Precip_cum_Iflo$I m a t+0.1593 * S w f a c \_a v g \_I f l o-I m a t+5.2879 * I n n \_a v g \_I f l o-I d r p-4.1489 * I n n \_m i n \_I f l o-I d r p+0.36$

\section{Linear regression number 16}

Mafruit $=0.0227 *$ Masec(n)_Iflo $-0.2846 *$ Lai(n)_Iflo $+0.0067 *$ Qnplante_Iflo $+0.0131 *$ Qfix_Iflo +0.2127 $*$ Masec(n)_Idrp + 0.0528*Lai(n)_Idrp + 0.0025*Qfix_Imat $-0.0077 *$ Ep_cum_Idrp-Imat $+1.9247 *$ Swfac_avg_Idrp-Imat $-1.1523 *$ Swfac_avg_Iflo-Imat $+4.2938 * I n n \_a v g \_I f l o-I d r p-3.7675 * I n n \_m i n \_I f l o-I d r p$ $+1.6917$

\section{Linear regression number 17:}

Mafruit $=0.0184 *$ Masec(n)_Iflo $-0.2846 *$ Lai(n)_Iflo $+0.0067 *$ Qnplante_Iflo $+0.0131 *$ Qfix_Iflo +0.2127 $*$ Masec(n)_Idrp + 0.0528*Lai(n)_Idrp + 0.0025*Qfix_Imat $-0.0077 *$ Ep_cum_Idrp-Imat $+1.9247 *$ Swfac_avg_Idrp-Imat $-1.1523 * S w f a c \_a v g \_I f l o-I m a t+4.2938 * I n n \_a v g \_I f l o-I d r p-3.7675 * I n n \_m i n \_I f l o-I d r p$ $+1.7071$

\section{Linear regression number 18:}

Mafruit $=-0.2114 * \operatorname{Masec}(n) \_I f l o-0.2846 *$ Lai $(n) \_I f l o+0.0067 *$ Qnplante_Iflo $+0.0143 *$ Qfix_Iflo +0.2127 $*$ Masec(n)_Idrp $+0.0528 *$ Lai $(n) \_I d r p+0.0025 *$ Qfix_Imat $-0.0077 *$ Ep_cum_Idrp-Imat $+1.9247 *$ Swfac_avg_Idrp-Imat $-1.1523 *$ Swfac_avg_Iflo-Imat $+4.2938 * I n n \_a v g \_I f l o-I d r p-3.7675 * I n n \_m i n \_I f l o-I d r p$ $+2.2973$

\section{Linear regression number 19:}

Mafruit $=-0.1891 * \operatorname{Masec}(n) \_I f l o-0.2846 *$ Lai $(n) \_I f l o+0.0067 *$ Qnplante_Iflo $+0.0143 *$ Qfix_Iflo +0.2127 $*$ Masec(n)_Idrp + 0.0528*Lai(n)_Idrp + 0.0025*Qfix_Imat - 0.0077*Ep_cum_Idrp-Imat + 1.9247* Swfac_avg_Idrp-Imat - 1.1523*Swfac_avg_Iflo-Imat $+4.2938 * I n n \_a v g \_I f l o-I d r p-3.7675 * I n n \_m i n \_I f l o-I d r p$ $+2.2385$ 